\title{
Bacterial endophytes from wild maize suppress Fusarium graminearum in modern maize and inhibit mycotoxin accumulation
}

\section{OPEN ACCESS}

Edited by:

Stéphane Hacquard Max Planck Institute for Plant Breeding Research, Germany

Reviewed by:

Birgit Mitter,

AlT Austrian Institute of Technology, Austria

James Francis White,

Rutgers, The State University of New

Jersey, USA

Lucy Seldin,

Federal University of Rio de Janeiro,

Brazil

*Correspondence:

Manish N. Raizada,

Department of Plant Agriculture, University of Guelph, 50 Stone Road,

Guelph, ON

N1G 2W1, Canada

raizada@uoguelph.ca

Specialty section: This article was submitted to

Plant Biotic Interactions,

a section of the journal

Frontiers in Plant Science

Received: 24 June 2015 Accepted: 15 September 2015

Published: 06 October 2015

Citation:

Mousa WK, Shearer CR, Limay-Rios V, Zhou T and Raizada MN (2015) Bacterial endophytes from wild

maize suppress Fusarium graminearum in modern maize and inhibit mycotoxin accumulation.

Front. Plant Sci. 6:805 doi: 10.3389/fpls.2015.00805

\author{
Walaa K. Mousa ${ }^{1,2}$, Charles R. Shearer ${ }^{1}$, Victor Limay-Rios ${ }^{3}$, Ting Zhou ${ }^{4}$ and \\ Manish N. Raizada ${ }^{1 *}$
}

${ }^{1}$ Department of Plant Agriculture, University of Guelph, Guelph, ON, Canada, ${ }^{2}$ Department of Pharmacognosy, Mansoura University, Mansoura, Egypt, ${ }^{3}$ Department of Plant Agriculture, University of Guelph, Ridgetown, ON, Canada, ${ }^{4}$ Guelph Food Research Centre, Agriculture and Agri-Food Canada, Guelph, ON, Canada

Wild maize (teosinte) has been reported to be less susceptible to pests than their modern maize (corn) relatives. Endophytes, defined as microbes that inhabit plants without causing disease, are known for their ability to antagonize plant pests and pathogens. We hypothesized that the wild relatives of modern maize may host endophytes that combat pathogens. Fusarium graminearum is the fungus that causes Gibberella Ear Rot (GER) in modern maize and produces the mycotoxin, deoxynivalenol (DON). In this study, 215 bacterial endophytes, previously isolated from diverse maize genotypes including wild teosintes, traditional landraces and modern varieties, were tested for their ability to antagonize F. graminearum in vitro. Candidate endophytes were then tested for their ability to suppress GER in modern maize in independent greenhouse trials. The results revealed that three candidate endophytes derived from wild teosintes were most potent in suppressing F. graminearum in vitro and GER in a modern maize hybrid. These wild teosinte endophytes could suppress a broad spectrum of fungal pathogens of modern crops in vitro. The teosinte endophytes also suppressed DON mycotoxin during storage to below acceptable safety threshold levels. A fourth, less robust anti-fungal strain was isolated from a modern maize hybrid. Three of the anti-fungal endophytes were predicted to be Paenibacillus polymyxa, along with one strain of Citrobacter. Microscopy studies suggested a fungicidal mode of action by all four strains. Molecular and biochemical studies showed that the P. polymyxa strains produced the previously characterized anti-Fusarium compound, fusaricidin. Our results suggest that the wild relatives of modern crops may serve as a valuable reservoir for endophytes in the ongoing fight against serious threats to modern agriculture. We discuss the possible impact of crop evolution and domestication on endophytes in the context of plant defense.

Keywords: Fusarium graminearum, Gibberella ear rot, maize, Zea diploperennis, parviglumis, endophyte, Paenibacillus, deoxynivalenol 


\section{Introduction}

Modern maize, belonging to the genus Zea, was domesticated in southern Mexico 9000 years ago from wild, annual tropical grasses called teosintes, with the primary ancestor being Parviglumis (Zea mays ssp. parviglumis) which survives today in the wild (Matsuoka et al., 2002). There are additional species of teosintes that continue to grow in the wild in Mexico and Central America including the perennial Zea diploperennis (Iltis and Doebley, 1980). Following its domestication into an edible crop ( $Z$. mays ssp. mays), maize was bred and spread by indigenous farmers throughout the Americas to give rise to diverse traditional landraces (Matsuoka et al., 2002). In the Twentieth Century, scientists created improved, commercial inbreds and hybrids such as the temperate hybrid, Pioneer 3751 (Smith et al., 2004). Wild maize has been reported to be more resistant to pests than their modern counterparts, perhaps due to loss of defense alleles and/or loss of the protective casing (fruitcase) enclosing the grains in modern varieties, as a result of breeding and domestication (Wang et al., 2005; Lange et al., 2014).

Though the increased disease susceptibility of modern maize has been attributed to changes in the plant genome, there may be additional explanations. Endophytes are microbes that inhabit the internal tissues of plants, including seeds, without causing disease symptoms (Wilson, 1995; Johnston-Monje and Raizada, 2011; White and Bacon, 2012; Mousa and Raizada, 2013). Some endophytes have been shown to help their host plants to combat pathogens (Mousa and Raizada, 2013, 2015). During maize evolution, domestication, breeding and migration, some endophytes were lost (Johnston-Monje and Raizada, 2011; Johnston-Monje et al., 2014), and it is also possible that endophytic genomes may have been modified-phenomena that might contribute to the increased disease susceptibility of modern maize.

Modern maize is susceptible to various pathogens including Fusarium graminearum, the fungus that causes Gibberella Ear Rot (GER). GER is a serious global disease particularly in Europe, the United States and Canada (van der Lee et al., 2014). In grain, F. graminearum produces deoxynivalenol (DON), a mycotoxin that inhibits DNA and protein synthesis, resulting in various toxicity effects in both humans and animals (Munkvold, 2003b; Voss, 2010; Hassan et al., 2015). In a 3 year survey, 59\% of maize samples tested from around the world were found to be contaminated with DON (Rodrigues and Naehrer, 2012).

Although the current disease management strategies to combat F. graminearum rely on breeding for resistance genotypes, optimizing cultural practices or use of fungicides, these strategies have achieved low to moderate success (Munkvold, 2003a; Edwards, 2004; Reid et al., 2009; Wegulo et al., 2011). A promising alternative strategy to manage Fusarium outbreaks and reduce mycotoxin contamination may be through the use of biological antagonists (Eilenberg, 2006; Bacon and Hinton, 2011; Chulze et al., 2014). We have recently reported that wild, traditional and modern maize possess endophytes that combat pathogens including F. graminearum in vitro (Johnston-Monje and Raizada, 2011; Johnston-Monje et al., 2014). Other studies have identified other biological control agents that combat $F$. graminearum including Bacillus and Pseudomonas spp. (Moussa et al., 2013; Shi et al., 2014). However, most of this research is preliminary, and effective commercial biological control is not currently available.

Here, we tested the hypothesis that the wild relatives of maize may possess endophytes that help their hosts to naturally combat F. graminearum. A library of bacterial endophytes, previously isolated from diverse maize genotypes including wild, traditional and modern varieties (Johnston-Monje and Raizada, 2011; Johnston-Monje et al., 2014), were screened for their ability to inhibit the growth of $F$. graminearum in vitro and suppress GER in planta.

\section{Materials and Methods}

\section{Source of Bacterial Endophytes}

A library of 215 bacterial endophytes was previously isolated in our lab to study the diversity of maize microbial endophytes (Johnston-Monje and Raizada, 2011). The endophytes were isolated from 14 diverse Zea genotypes, including wild teosintes (Zea mays ssp. parviglumis, Zea mays ssp. mexicana, Zea diploperennis, Zea nicaraguensis), ancient and traditional Mexican landraces of modern maize (Zea mays ssp. mays: Gaspe yellow Flint, Cristalino de Chihuahua, Chapalote, Mixteco, Bolita, Jala, Nal-Tel, Tuxpeno) and modern maize varieties (Zea mays ssp. mays: Pioneer 3751 and B73). The endophytes analyzed from wild, traditional and modern genotypes represented 46,33 , and $21 \%$ of the library, respectively, with approximately half the library isolated from non-wild, post-domesticated maize (54\%) (Table S3).

\section{Antifungal Screening}

Overnight cultures of each endophyte were used to screen endophytic bacteria for in vitro inhibition of growth of $F$. graminearum (obtained from Agriculture and Agrifood Canada, Guelph, ON) using the dual culture method. Each bacterial endophyte was cultured in liquid broth (LB, Luria-Bertani, composed of $10 \mathrm{~g} \mathrm{NaCl}, 5 \mathrm{~g}$ yeast extract, $10 \mathrm{~g}$ tryptone, per liter), grown for $1-3$ days at $37^{\circ} \mathrm{C}$ with shaking at $225 \mathrm{rpm}$ then centrifugation for $5 \mathrm{~min}$, followed by resuspension in PBS buffer to an $\mathrm{OD}_{600}$ of 0.4-0.6 (Spectromax, serial \# MN03135, USA). F. graminearum was grown for $48 \mathrm{~h}\left(25^{\circ} \mathrm{C}, 100 \mathrm{rpm}\right)$ in liquid potato dextrose broth media (Catalog \# P6685, Sigma Aldrich, USA), then mycelia was added to melted, cooled PDA media ( $1 \mathrm{ml}$ of fungus into $100 \mathrm{ml}$ of media), mixed and poured into Petri dishes $(100 \times 15 \mathrm{~mm})$, then allowed to re-solidify. Wells (11 mm diameter) were created in this pathogen-embedded agar by puncturing with sterile glass tubes, into which the endophyte cultures were applied $(200 \mu \mathrm{l}$ per well). The agar plates were incubated at $30^{\circ} \mathrm{C}$ for $48 \mathrm{~h}$ in darkness. The radius of each zone of inhibition was measured (mm). The commercial broad-spectrum fungicides, Amphotericin B (Catalog \#A2942, Sigma Aldrich, USA) and Nystatin (Catalog \#N6261, Sigma Aldrich, USA), were used as positive controls at concentrations of 5 and $10 \mu \mathrm{g} / \mathrm{ml}$, respectively. LB was used as a negative control. Each endophyte was screened in three independent replicates. 


\section{Anti-fungal Target Spectrum of the Candidate Endophytes}

Endophytes that tested positive for activity against $F$. graminearum were re-screened for activity against a diversity of other fungal species including crop pathogens (from the Agriculture and Agrifood Canada Fungal Type Collection, Guelph, ON, Canada) using the dual culture method (described above) to characterize the activity spectrum of each endophyte. The crop fungi tested included: Alternaria alternata, Alternaria arborescens, Aspergillus flavus, Aspergillus niger, Bionectria ochroleuca, Davidiella (Cladosporium) tassiana, Diplodia pinea, Diplodia seriata, Epicoccum nigrum, Fusarium lateritium, Fusarium sporotrichioides, Fusarium avenaceum (Gibberella avenacea, two isolates), Nigrospora oryzae, Nigrospora sphaerica, Paraconiothyrium brasiliense, Penicillium expansum, Penicillium afellutanum, Penicillium olsonii, Rosellinia corticium, Torrubiella confragosa, Trichoderma hamatum and Trichoderma longibrachiatum.

\section{Molecular Identification of Candidate Endophytic Bacteria Using 16S rDNA and 23S rDNA}

For taxonomic identification of candidate endophytic bacteria, a standard PCR protocol was used (Johnston-Monje and Raizada, 2011). Bacterial genomic DNA was extracted (GenElute Bacterial Genomic DNA kit, NA2110-1KT, Sigma) and quantified using a Nanodrop machine (Thermo Scientific, USA). The extracted DNA was used to amplify $16 \mathrm{~S}$ rDNA and $23 \mathrm{~S}$ rDNA using PCR.

\section{For 16S rDNA Amplification}

A PCR master mix $(20 \mu \mathrm{l})$ was made as follows: 50 ng DNA were added $(2.5 \mathrm{ng} / \mu \mathrm{l}$ was the final DNA concentration in the PCR reaction), $2.5 \mu \mathrm{l}$ Standard Taq Buffer $(10 \times)$ (New England Biolabs), $0.5 \mu \mathrm{l}$ of $25 \mathrm{mM}$ dNTP mix, $1 \mu \mathrm{l}$ of $10 \mathrm{mM}$ 1492r primer with sequence GGTTACCTTGTTACGACTT, $1 \mu \mathrm{l}$ of $10 \mathrm{mM}$ 799f primer with sequence AACMGGATTAGATACCCKG (M and $\mathrm{K}$ refer to degenerate nucleotides, where $\mathrm{M}$ is $\mathrm{A}$ or $\mathrm{C}$ and $\mathrm{K}$ is $\mathrm{G}$ or $\mathrm{T}), 0.25 \mu \mathrm{l}$ of $50 \mathrm{mM} \mathrm{MgCl}, 0.25 \mu \mathrm{l}$ of Standard Taq (10 U/ $\mu \mathrm{l}$, New England Biolabs), and double distilled water up to $20 \mu \mathrm{l}$ total.

\section{For 23S rDNA Amplification}

A PCR master mix $(20 \mu \mathrm{l})$ was made as described above using $1 \mu \mathrm{l}$ of $10 \mathrm{mM}$ 23S $6 \mathrm{~F}$ primer with sequence $5^{\prime}$ GCGATTTCYGAAYGGGGRAACCC and $1 \mu \mathrm{l}$ of $10 \mathrm{mM} 23 \mathrm{~S}$ $\mathrm{R}$ primer with sequence $5^{\prime}$ - TTCGCCTTTCCCTCACGGTACT (where $\mathrm{Y}$ is $\mathrm{C}$ or $\mathrm{T}$ and $\mathrm{R}$ is $\mathrm{A}$ or G) (Anthony et al., 2000).

For both $16 \mathrm{~S}$ rDNA and 23S rDNA, the PCR amplification conditions were: $96^{\circ} \mathrm{C}$ for $3 \mathrm{~min}$, followed by 35 amplification cycles $\left(94^{\circ} \mathrm{C}\right.$ for $30 \mathrm{~s}, 48^{\circ} \mathrm{C}$ for $30 \mathrm{~s}, 72^{\circ} \mathrm{C}$ for $\left.90 \mathrm{~s}\right)$, and a final extension at $72^{\circ} \mathrm{C}$ for $7 \mathrm{~min}$, using a PTC200 DNA Thermal Cycler (MJ Scientific, USA). Finally, the PCR products were separated on $1.5 \%$ agarose gels at $\leq 5 \mathrm{~V} / \mathrm{cm}$, then the bands were visualized under UV light; 700 and 400 bp bands were excised for $16 \mathrm{~S}$ rDNA and 23S rDNA, respectively and eluted from the gels (Illustra GFX 96 PCR Purification kit, GE Healthcare, USA). The purified DNA was sequenced at the Genomic Facility Laboratory at the University of Guelph. For 16S, primers 1492r and 799f were used for sequencing, while for 23S, primer 23S 6F was used. Bacterial strains were identified based on $16 \mathrm{~S}$ rDNA and 23S rDNA sequence comparisons using BLAST searches to GenBank. To assist with taxonomic identification, 16S rDNA sequences for the three Paenibacillus sp. were used to generate a phylogenetic tree using Phylogeny.fr (Dereeper et al., 2008, 2010).

\section{Scanning Electron Microscope (SEM) Imaging of Endophytes}

Scanning electron microscopy imaging was conducted to visualize the external appearance of candidate bacteria following a standard protocol (Hayat, 1989). Bacterial cultures were plated on LB plates, incubated for $24 \mathrm{~h}$ then suspended and washed in phosphate buffer ( $\mathrm{pH}$ 7). A drop of the suspension was placed on a carbon disc and left to dry for $1 \mathrm{~h}$. The dried bacteria was washed with phosphate buffer then fixed by adding $2 \%$ glutaraldehyde for $1 \mathrm{~h}$. The fixed bacteria was then treated with $1 \%$ osmium tetroxide for $30 \mathrm{~min}$, then gradually dehydrated using an ethanol series (50, 70, 80, 90, and 100\%) followed by critical point drying. The dried bacterial films were coated with gold and examined by SEM (Hitachi S-570 SEM, Hitachi High Technologies, Tokyo, Japan) at the Imaging Facility, Department of Food Science, University of Guelph.

\section{In vitro Interaction between Each Endophyte and F. graminearum}

The in vitro interaction between $F$. graminearum and each bacterial endophyte was studied microscopically. Each microscope slide was coated with a thin layer of PDA, then $50 \mu \mathrm{l}$ of bacterial endophyte culture (grown overnight in LB incubated at $37^{\circ} \mathrm{C}, 250 \mathrm{rpm}$ ) was applied adjacent to $50 \mu \mathrm{l}$ of F. graminearum mycelia (grown for $24-48 \mathrm{~h}$ in potato dextrose broth at $25^{\circ} \mathrm{C}, 100 \mathrm{rpm}$ ). Each slide was incubated at $25^{\circ} \mathrm{C}$ for $24 \mathrm{~h}$ then stained with the vitality stain, neutral red (Sigma Aldrich, Catalog \#57993) or Evans blue (Sigma Aldrich, Catalog \# E2129) by placing $100 \mu \mathrm{l}$ of stain on the slide, followed by a $3-$ 5 min incubation at room temperature, then washing 3-4 times with deionized water. A commercial biological control agent with a fungicidal mode of action (Bacillus subtilis QST713, Bayer CropScience, Batch \#00129001) was used as a positive control $(100 \mathrm{mg} / 10 \mathrm{ml})$. Pictures were taken using light microscopes (MZ8, Leica, Wetzlar, Germany for neutral red staining; and a BX51 microscope, Olympus, Tokyo, Japan for Evans blue staining). There were 3-4 replicates for each slide.

\section{PCR Based Approach to Detect the Fusaricidin Biosynthetic Gene in the Paenibacillus Endophyte Strains}

In order to detect the presence of a candidate fusaricidin synthetase gene (fusA) in the Paenibacillus endophyte strains, two oligonucleotides (FusAF and FusAR) were designed based on the fusA sequence (GenBank accession \#EU184010) using Primer3 software. For fusA amplification, a PCR master mix $(20 \mu \mathrm{l})$ was made as follows: $50 \mathrm{ng}$ DNA were added $(2.5 \mathrm{ng} / \mu \mathrm{l}$ was the final DNA concentration in the PCR reaction), $50 \mathrm{ng}$ DNA, $2.5 \mu \mathrm{l}$ Standard Taq Buffer $(10 \times)$ (New England Biolabs), $0.5 \mu \mathrm{l}$ of $25 \mathrm{mM}$ dNTP mix, $0.25 \mu \mathrm{l}$ 


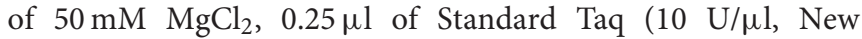
England Biolabs), $1 \mu \mathrm{l}$ of primer FusAF with sequence $5^{\prime}$ AGGCAAGCTTTGACTTGGAA $-3^{\prime}$ and $1 \mu \mathrm{l}$ of primer FusAR with sequence $5^{\prime}$ - CGCTTGCTCAGACCATACAA $-3^{\prime}$ and double distilled water up to $20 \mu$ l total. The PCR amplification conditions were: $96^{\circ} \mathrm{C}$ for $3 \mathrm{~min}$, followed by 35 amplification cycles $\left(94^{\circ} \mathrm{C}\right.$ for $30 \mathrm{~s}, 48^{\circ} \mathrm{C}$ for $30 \mathrm{~s}, 72^{\circ} \mathrm{C}$ for $\left.90 \mathrm{~s}\right)$, and a final extension at $72^{\circ} \mathrm{C}$ for $7 \mathrm{~min}$, using a PTC200 DNA Thermal Cycler (MJ Scientific, USA). The PCR products were separated on $1.5 \%$ agarose gels at $\leq 5 \mathrm{~V} / \mathrm{cm}$, then the bands were visualized under UV light; bands were excised and eluted from the gels (Illustra GFX 96 PCR Purification kit, GE Healthcare, USA). The purified DNA was sequenced at the Genomic Facility Laboratory at the University of Guelph. The corresponding gene was identified based on best BLAST matches to Genbank.

\section{Biochemical Detection of Fusaricidins in Endophyte Culture Filtrates Using LC-MS}

To detect the presence of fusaricidins biochemically in Paenibacillus spp., endophytes were grown for $48 \mathrm{~h}$ on Katznelson and Lochhead liquid medium (Paulus and Gray, 1964), harvested by freeze drying, then the lyophilized powder from each strain was extracted by methanol. The methanolic extracts were run on a Luna C18 column with a gradient of $0.1 \%$ formic acid and $0.1 \%$ formic in acetonitrile. Peaks were analyzed by mass spectroscopy (Agilent 6340 Ion Trap), ESI, positive ion mode. LC-Mass analysis was conducted at the Mass Spectroscopy Facility, McMaster University, Ontario, Canada. The $\mathrm{m} / \mathrm{z}$ ratios were compared to the published literature (Kajimura and Kaneda, 1996, 1997; Beatty and Jensen, 2002).

\section{GFP-tagging for Ecological Tracking in Planta}

In order to test the ability of candidate anti-Fusarium endophytes to colonize a modern maize hybrid, the endophytes were subjected to tagging with green fluorescent protein (GFP) followed by in planta visualization using confocal scanning microscopy.

\section{To Prepare Competent Cells}

One liter of LB broth was inoculated with $10 \mathrm{ml}$ bacterial culture grown overnight $\left(37^{\circ} \mathrm{C}\right.$ at $\left.250 \mathrm{rpm}\right)$ until early log phase $\left(\mathrm{OD}_{600}=0.4-0.6\right)$. The cells were harvested by chilling for $15 \mathrm{~min}$ on ice and centrifuged at $4000 \times g$ for $15 \mathrm{~min}$ at $4^{\circ} \mathrm{C}$. The pellets were then re-suspended in cold water and centrifuged two times. Finally, the pellets were re-suspended in cold $10 \%$ glycerol, centrifuged and re-suspended in $3 \mathrm{~mL}$ of $10 \%$ glycerol from which $40 \mu \mathrm{l}$ aliquots were made and frozen at $-80^{\circ} \mathrm{C}$.

\section{GFP Plasmid Transformation}

A wide-host promoter plasmid, pDSK-GFPuv (Wang et al., 2007) was used to transform E.coli DH5 $\alpha$ (Catalog \#EC6P095H, Epicenter, Madison, USA), which was then stored at $-80^{\circ} \mathrm{C}$. The plasmid was extracted from E.coli using a standard protocol (Catalog \# 732-6100, BioRad Inc., USA) then introduced into bacterial cells by electroporation (Calvin and Hanawalt, 1988). Suspensions of $40 \mu \mathrm{l}$ cold competent cells were mixed with $1 \mu \mathrm{l}$ of plasmid DNA $(240 \mathrm{ng} / \mu \mathrm{l})$ then electroporated at $1.6 \mathrm{KV}$ for $1 \mathrm{~s}$ using a Bio-Rad Gene Pulser 200/2.0 (Bio-Rad Hercules, USA). After electroporation, cells were incubated for $1 \mathrm{~h}$ in $1 \mathrm{ml}$ of LB at $37^{\circ} \mathrm{C}$ with shaking at $250 \mathrm{rpm}$. Transformed cells were plated on LB agar containing Kanamycin $(35 \mu \mathrm{g} / \mu \mathrm{l})$ and incubated for $24 \mathrm{~h}$ at $37^{\circ} \mathrm{C}$, then the plate was examined for fluorescent colonies (Illumatool, \#LR 92240, Lightools Research, USA).

\section{To Visualize GFP-tagged Endophyte Cells inside Maize Tissues}

Modern maize seeds (Ontario maize hybrid P35F40, see below) were surface sterilized, coated with GFP-tagged endophyte (see below for details), and planted on wet paper towels. One-weekold seedlings were stained with propidium iodide $(1 \mathrm{mg} / \mathrm{ml})$ (Sigma Aldrich, Catalog \#P4170) then washed with deionized water. The seedlings were screened by a TCS SP2 confocal laser scanning microscope (Leica Microsystems, Mannheim, Germany) at the Imaging Facility, University of Guelph. The conditions for confocal microscopy were as follows: excitation at $488 \mathrm{~nm}$ with an Argon laser and at $543 \mathrm{~nm}$ with a green helium laser (emission ranges $=504-532 \mathrm{~nm}$ and $524-699 \mathrm{~nm}$, respectively), pinhole $[\mathrm{Au}]=1.0$ airy, objective lens $=63 \times$ oil immersion, and frame average $=3$ times.

\section{Suppression of GER in Greenhouse Trials}

The candidate endophytes that suppressed the growth of $F$. graminearum in vitro were tested for their ability to suppress GER in greenhouse trials (Crop Science Greenhouse Facility, University of Guelph):

\section{Seed Treatment}

Seeds of a susceptible commercial maize hybrid (P35F40) were surface sterilized as follows: seeds were washed in $0.1 \%$ Triton X-100 detergent for $10 \mathrm{~min}$ with shaking; the detergent was decanted, $3 \%$ sodium hypochlorite was added for $10 \mathrm{~min}$, followed by rinsing with autoclaved, distilled water, washing with $95 \%$ ethanol for $10 \mathrm{~min}$; and finally the samples were washed 5-6 times with autoclaved, distilled water. Effective surface sterilization was ensured by inoculating the last wash on $\mathrm{LB}$ and $\mathrm{PDA}$ plates at 37 and $25^{\circ} \mathrm{C}$, respectively; all washes showed no growth. The sterilized seeds were then coated with endophytic inoculants (on the day of planting). To prepare endophytic bacterial inoculants, bacteria were grown for $24 \mathrm{~h}$ at $37^{\circ} \mathrm{C}$ in liquid LB medium, centrifuged, washed and suspended in PBS buffer to an $\mathrm{OD}_{600}$ of 0.5 . Thereafter, $500 \mu \mathrm{l}$ of each bacterial suspension were mixed with $10 \mathrm{ml}$ polyvinyl pyrrolidine (PVP, Catalog \# 9003398, Sigma Aldrich, USA) as a seed-coating agent; then incubated with the seeds for $2 \mathrm{~h}$ on a horizontal shaker (Serial \#980216M, National Labnet Company, USA). Seeds coated with the endophytes or buffer control were then germinated on wet paper towels and kept in the dark for 7 days; uniformly sized seedlings were transferred into pots containing Turface clay (Turface Athletics Inc., USA) in the greenhouse under the following growth conditions: $\left(28^{\circ} \mathrm{C} / 20^{\circ} \mathrm{C}, 16 \mathrm{~h}: 8 \mathrm{~h}\right.$, $\geq 800 \mu \mathrm{mol} \mathrm{m} \mathrm{m}^{-2} \mathrm{~s}^{-1}$ at pot level, with high pressure sodium and metal halide lamps supplemented with GroLux bulbs) using drip irrigation with modified Hoagland's solution until maturity (Gaudin et al., 2011). 


\section{Pathogen Introduction}

Pathogen spores were prepared as follows: the liquid medium used for spore suspension was prepared with the following composition per liter in distilled water: $2 \mathrm{~g} \mathrm{KH}_{2} \mathrm{PO}_{4}, 2 \mathrm{~g} \mathrm{KNO}$, $1 \mathrm{~g} \mathrm{MgSO}_{4}, 1 \mathrm{~g} \mathrm{KCl}, 1 \mathrm{~g}$ dextrose, $20 \mathrm{mg} / 100 \mathrm{ml}$ (of each) of minor elements $\left(\mathrm{FeCl}_{2}, \mathrm{MnSO}_{4}, \mathrm{ZnSO}_{4}\right)$. Approximately $350 \mathrm{ml}$ of the liquid medium was added to $2 \mathrm{~L}$ flasks and autoclaved at $121^{\circ} \mathrm{C}$ for $10 \mathrm{~min}$. After cooling to room temperature, either 3-4 PDA plugs of F. graminearum isolate or $10 \mathrm{ml}$ of liquid conidia suspension was added aseptically to each flask, which was incubated on a shaker table at room temperature under 12:12 h UV light: dark cycle for approximately 2 weeks. Using a haemocytometer, the solution was standardized to 20,000 spores $/ \mathrm{ml}$ before being stored in the fridge or used in the greenhouse directly. One $\mathrm{ml}$ of $F$. graminearum spore suspension was applied first to silks beginning after their emergence.

\section{Endophyte Silk Spray Treatment}

To ensure high titre of the endophytes, they were introduced a second time, by spraying $1 \mathrm{ml}$ of each endophyte $\left(\mathrm{OD}_{600}\right.$ of 0.5 , grown in LB) simultaneously with the pathogen inoculant, and then again at 3 days after pathogen inoculation.

\section{Control Treatments}

For the positive control group, seeds were coated only with PVP followed by prothioconazole fungicide spraying (PROLINE ${ }^{\circledR}$ 480 SC, Bayer Crop Science) at the post-silking stage prior to infection with the fungal pathogen. The negative control was seeds coated only with PVP, then sprayed at silking with $1 \mathrm{ml}$ of F. graminearum spore suspension only.

\section{Experimental Design}

There were 20 plants arranged in a randomized block design per each treatment group. The trial was repeated independently in the summers of 2012 and 2013. In the second trial, to increase disease severity, the humidity around the ears was artificially increased by placing plastic bags around the ears. The plants were grown until full maturity.

\section{Disease Assessments}

At full maturity stage, ears were phenotyped visually for the percentage of apparent infection, scored as the length of diseased area from the ear tip (infection site) relative to the total length of each respective ear. The other phenotype measured was average grain yield per plant (g) at harvest. Results were analyzed and compared by Mann-Whitney $t$-tests $(P<0.05)$.

\section{Suppression of DON Production}

Maize kernels were ground for $40 \mathrm{~s}$ to a texture that would pass through a 20-mesh sieve using an M2 Stein mill (Fred Stein Lab, Inc. Atchinson, KS, USA). Ground samples (5 g) were diluted in distilled water at a ratio of 1:5 (w/v) and shaken vigorously for 3 min using a bench top reciprocal Eberbach shaker equipped with a flask carrier (Eberbach Corp, Ann Arbor, MI).

A $2 \mathrm{ml}$ aliquot of the suspension fluid was transferred into a microcentrifuge tube and spun at $8000 \mathrm{rpm}$ for $60 \mathrm{~s}$. Sample aliquots were subsequently diluted in distilled water when appropriate. ELISA analysis was carried out with the EZToxTM DON Test (Diagnostix Ltd., Mississauga, ON, Canada) following the manufacturer's protocol with a detection limit of $0.1 \mu \mathrm{g} / \mathrm{g}$. There were three replicates for each treatment. Results were analyzed and compared by the Mann-Whitney $t$-test $(P<0.05)$.

\section{DON Detoxification}

To test for the ability of the candidate endophytes to directly detoxify DON into epi- DON, in vitro liquid chromatography coupled to a diode array detector (LC-DAD) was used. Endophytes were grown in $5 \mathrm{ml} \mathrm{LB}$ for $48 \mathrm{~h}$ at $250 \mathrm{rpm}$ with 20-ppm deoxynivalenol (DON, Catalog \#D0156, Sigma-Aldrich, USA). The cultures were diluted to 2 ppm DON with MiliQ water. Then, DON was extracted from the bacterial cultures using monoclonal antibody-based affinity chromatography (VICAM, DONtest $^{\mathrm{TM}}$ HPLC, G1005) then subjected to HPLC analysis to detect DON and epi-DON compared to control buffers. The samples were run on a C18 column $(250 \times 4.6 \mathrm{~mm}$, product \# 00G-4396-E0, Phenomenex Inc., USA) with an isocratic wateracetonitrile (90:10) system. Peaks were detected by photodiode array spectrophotometer equipped within an Agilent 1200 Infinity Series HPLC (Agilent, USA). There were three replicates for each endophyte tested.

\section{Statistical Analyses}

All statistical analysis was performed using Prism Software version 5 (GraphPad Software, USA).

\section{Results}

\section{Antifungal Screening}

The dual culture method was used to screen 215 bacterial endophytes, previously isolated from diverse maize genotypes (Figures 1A,B), for their ability to suppress the growth of $F$. graminearum. Zones of inhibition of $F$. graminearum were measured after $24-48 \mathrm{~h}$ of co-incubation (Figures 1C,D). The results revealed that four bacterial endophytes could consistently inhibit the growth of F. graminearum (strains 1D6, 3H9, 4G12, and $4 \mathrm{G} 4$ ). Strain $1 \mathrm{D} 6$ resulted in the greatest growth inhibition, while $3 \mathrm{H} 9$ caused the least growth inhibition to F. graminearum (Figure 1D). Three of these endophytes were isolated from wild maize genotypes (teosintes): strain 1D6 from $Z$. diploperennis and strains 4G12 and 4G4 from Parviglumis, the direct ancestor of modern maize (Figures 1A,2A). The remaining candidate endophyte (strain 3H9) was isolated from a modern commercial variety (Z. mays ssp. mays, Pioneer 3751 hybrid).

\section{Anti-fungal Target Spectrum of the Candidate Endophytes}

Using the dual culture method, endophytes that tested positive for activity against F. graminearum, were re-screened for activity against a collection of fungi including crop pathogens. Each candidate endophyte was screened in three independent replicates. Endophytes 1D6, 4G12, and 4G4 from the wild teosintes showed the highest spectrum of activity as they inhibited the growth of 20,19 , and 20 fungi, respectively, out of 20 


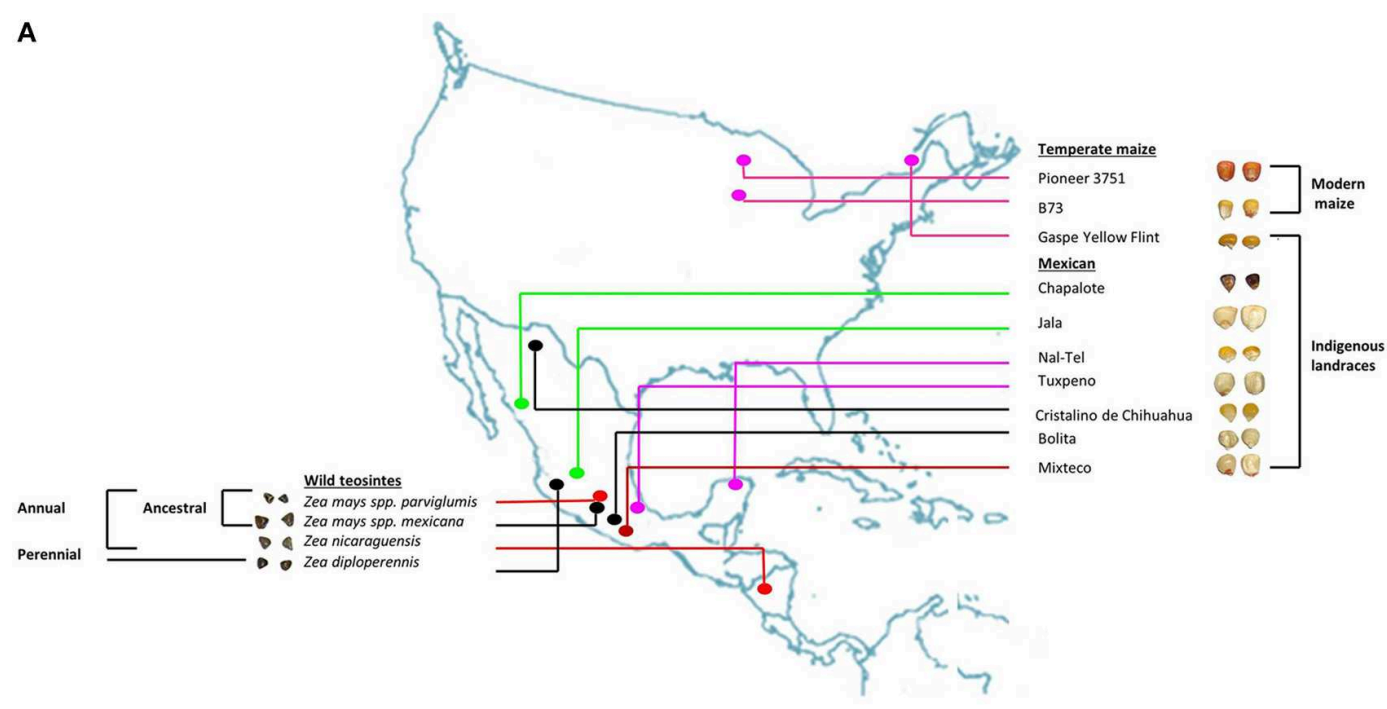

B
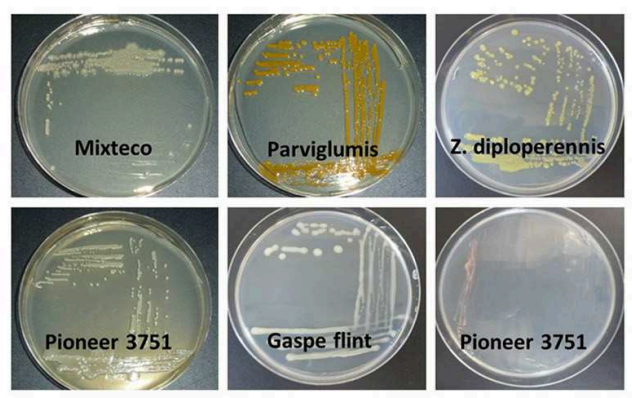

C

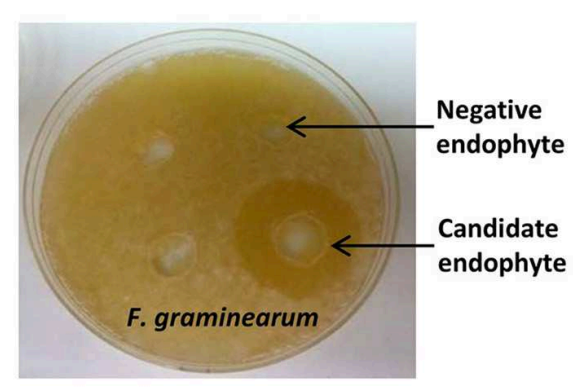

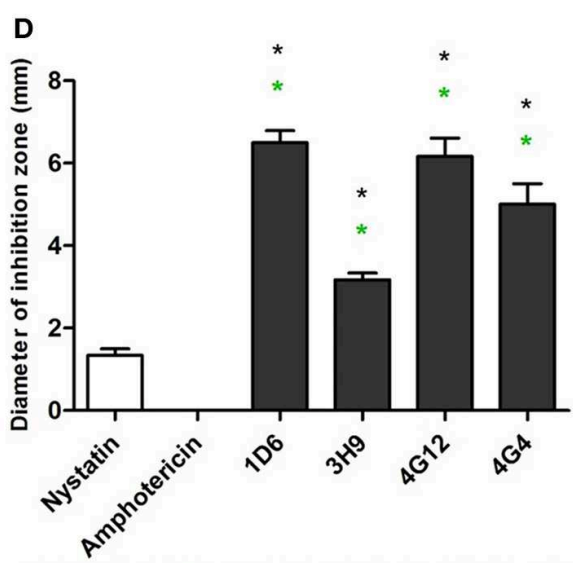

Inhibition of $F$. graminearum growth in vitro

FIGURE 1 | Origin of endophytes used in this study and results of the in vitro anti-Fusarium screen. (A) A map showing the origin of maize genotypes previously used to isolate the endophytic library. (B) Examples of endophytes from the library isolated from different Zea genotypes as indicated. (C) Example of an endophyte culture showing suppression of $F$. graminearum hyphae (white) using the dual culture method. (D) Quantification of the inhibitory effect of the endophytes or fungicide controls, amphotericin B and nystatin (at concentrations of 5 and $10 \mu \mathrm{g} / \mathrm{ml}$, respectively), on the growth of $F$. graminearum in vitro. For these experiments, $n=3$. The error bars indicate the standard error of the mean. The black asterisk indicates that the treatment means are significantly different from the fungicide Nystatin at $p \leq 0.05$. The green asterisk indicates that the treatment means are significantly different from the fungicide Amphotericin at $p \leq 0.05$.

tested fungi (other than F. graminearum). Endophyte $3 \mathrm{H} 9$ from modern maize showed a narrow activity spectrum as it inhibited the growth of only one fungus in addition to F. graminearum (Table 1).

\section{Molecular Identification of Candidate Endophytic Bacteria}

$16 \mathrm{~S}$ rDNA and 23S rDNA sequencing were used for taxonomic identification of endophytic bacteria. BLAST searching against 


\begin{tabular}{|c|c|c|c|c|c|c|}
\hline ID & Maize host & Tissue & $\begin{array}{c}\text { Best BLAST } \\
\text { Match }\end{array}$ & $\begin{array}{c}\text { BLAST } \\
\text { E-value }\end{array}$ & $\begin{array}{c}\text { Percent Maximum } \\
\text { Identity to 16S } \\
\text { rDNA }\end{array}$ & $\begin{array}{c}\text { Percent Maximum } \\
\text { Identity to 23S } \\
\text { rDNA }\end{array}$ \\
\hline ID6 & Z. diploperennis & Seeds & Paenibacillus sp. & 0.0 & $97 \%$ & $99 \%$ \\
\hline $3 \mathrm{H} 9$ & $\begin{array}{c}\text { Z. mays ssp mays } \\
\text { (hybrid Pioneer } 3751)\end{array}$ & Seeds & Paenibacillus sp. & 0.0 & $92 \%$ & $100 \%$ \\
\hline 4G12 & $\begin{array}{c}\text { Z. mays ssp parviglumis } \\
\text { 4G4 }\end{array}$ & Roots & Citrobacter sp. & 0.0 & $99 \%$ & $99 \%$ \\
\hline
\end{tabular}

B

_Paenibacillus_popilliae_AB073198

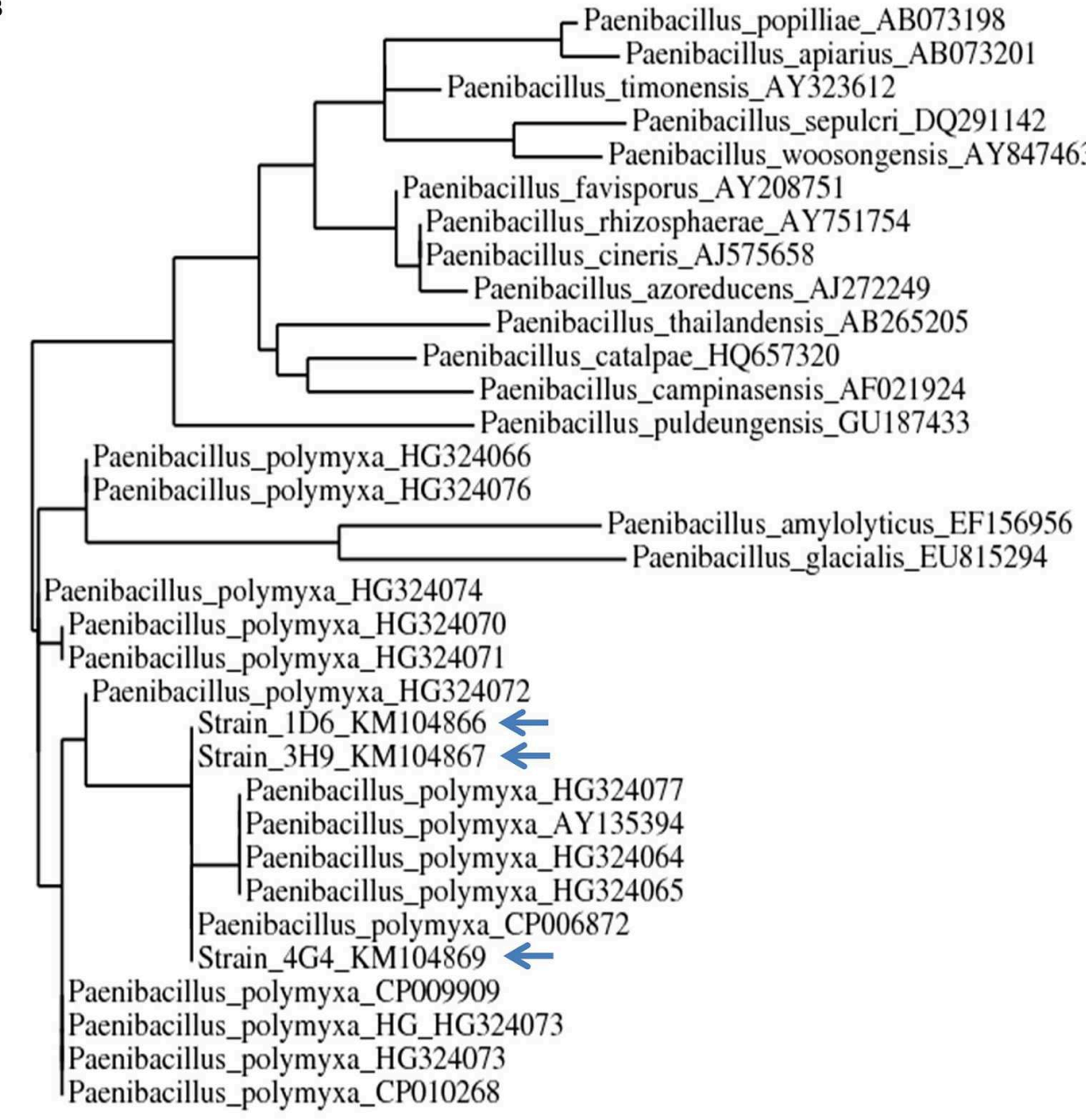

0.1

FIGURE 2 | Taxonomic characterization of candidate anti-Fusarium endophytes. (A) Details of the taxonomic identification of the anti-Fusarium endophytes using 16 S rDNA and 23S rDNA, and the tissue and host from which the endophytes were originally isolated. (B) 165 rDNA based phylogenetic tree of the three predicted Paenibacillus sp.

the Genbank database suggested that three of the candidate endophytes, 1D6, 3H9, and 4G4, most closely resemble Paenibacillus sp. while $4 \mathrm{G} 12$ resembles a Citrobacter sp.
(Figure 2, Table S1). GenBank accession numbers for strains 1D6, 3H9, 4G12, and 4G4 using 16S rDNA are KM104866, KM104867, KM104868, and KM104869, respectively. GenBank 
TABLE 1 | Effect of the candidate bacterial endophytes on the growth of diverse crop fungal pathogens in vitro.

\begin{tabular}{|c|c|c|c|c|c|c|}
\hline \multirow[t]{2}{*}{ Target fungal species } & \multicolumn{6}{|c|}{ Mean diameter of inhibition zone with each endophyte (mm) } \\
\hline & Nystatin $(10 \mu \mathrm{g} / \mathrm{ml})$ & Amphotericin $(5 \mu \mathrm{g} / \mathrm{ml})$ & 1D6 & $3 \mathrm{H} 9$ & 4G12 & 4G4 \\
\hline Alternaria alternata & $0.0 \pm 0.0$ & $0.0 \pm 0.0$ & $3.0 \pm 0.2^{\star} \#$ & $0.0 \pm 0.0$ & $4.5 \pm 0.2^{\star} \#$ & $5.0 \pm 0.0^{\star} \#$ \\
\hline Alternaria arborescens & $0.0 \pm 0.0$ & $0.0 \pm 0.0$ & $5.5 \pm 0.2^{*} \#$ & $0.0 \pm 0.0$ & $5.5 \pm 0.2^{*} \#$ & $5.0 \pm 0.2^{\star} \#$ \\
\hline Aspergillus flavus & $2.0 \pm 0.2$ & $0.0 \pm 0.0$ & $5.5 \pm 0.3^{\star} \#$ & $0.0 \pm 0.0^{*}$ & $3.5 \pm 0.2^{*} \#$ & $4.0 \pm 0.0^{\star} \#$ \\
\hline Aspergillus niger & $0.0 \pm 0.0$ & $2.0 \pm 0.0$ & $6.5 \pm 0.3^{\star} \#$ & $0.0 \pm 0.0 \#$ & $5.0 \pm 0.0^{*} \#$ & $7.0 \pm 1.0^{\star} \#$ \\
\hline Bionectria ochroleuca & $2.0 \pm 0.2$ & $0.5 \pm 0.2$ & $5.5 \pm 0.2^{*} \#$ & $3.5 \pm 0.3^{*} \#$ & $6.0 \pm 0.2^{*} \#$ & $6.5 \pm 0.2^{*} \#$ \\
\hline Davidiella tassiana & $1.5 \pm 0.2$ & $0.5 \pm 0.3$ & $5.0 \pm 0.3^{\star} \#$ & $0.0 \pm 0.0^{*} \#$ & $4.5 \pm 0.7^{\star} \#$ & $5.0 \pm 0.0^{\star} \#$ \\
\hline Diplodia pinea & $2.5 \pm 0.2$ & $3.0 \pm 0.2$ & $6.5 \pm 0.3^{\star} \#$ & $0.0 \pm 0.0^{*} \#$ & $5.5 \pm 0.2^{*} \#$ & $6.0 \pm 0.0^{\star} \#$ \\
\hline Diplodia seriata & $3.0 \pm 0.2$ & $2.0 \pm 0.2$ & $3.0 \pm 0.2 \#$ & $0.0 \pm 0.0^{*} \#$ & $0.0 \pm 0.0^{*} \#$ & $1.5 \pm 0.2^{\star} \#$ \\
\hline Epicoccum nigrum & $0.0 \pm 0.0$ & $0.0 \pm 0.0$ & $1.5 \pm 0.2^{\star} \#$ & $0.0 \pm 0.0$ & $4.0 \pm 0.0^{*} \#$ & $3.0 \pm 0.2^{*} \#$ \\
\hline Fusarium avenaceum (isolate 1) & $2.5 \pm 0.3$ & $3.0 \pm 0.6$ & $7.0 \pm 0.2^{\star} \#$ & $0.0 \pm 0.0^{\star} \#$ & $4.5 \pm 0.2^{*} \#$ & $3.0 \pm 0.2^{*}$ \\
\hline Fusarium graminearum & $1.5 \pm 1.6$ & $0.0 \pm 0.0$ & $6.5 \pm 0.3^{\star} \#$ & $3.0 \pm 0.2^{\star} \#$ & $6.0 \pm 0.4^{\star} \#$ & $5.0 \pm 0.5^{\star} \#$ \\
\hline Fusarium lateritium & $0.0 \pm 0.0$ & $1.0 \pm 0.2$ & $1.5 \pm 0.3^{\star} \#$ & $0.0 \pm 0.0 \#$ & $4.0 \pm 0.5^{*} \#$ & $5.5 \pm 0.3^{\star} \#$ \\
\hline Fusarium sporotrichioides & $1.0 \pm 0.2$ & $1.0 \pm 0.2$ & $4.0 \pm 0.0^{\star} \#$ & $0.0 \pm 0.0^{*} \#$ & $5.5 \pm 0.7^{\star} \#$ & $4.0 \pm 0.0^{\star} \#$ \\
\hline Fusarium avenaceum (isolate 2) & $0.0 \pm 0.0$ & $0.0 \pm 0.0$ & $3.5 \pm 0.2^{\star} \#$ & $0.0 \pm 0.0$ & $2.0 \pm 0.0^{*} \#$ & $6.5 \pm 0.2^{\star} \#$ \\
\hline Nigrospora oryzae & $0.0 \pm 0.0$ & $0.0 \pm 0.0$ & $6.0 \pm 0.4^{\star} \#$ & $0.0 \pm 0.0$ & $4.0 \pm 0.5^{\star} \#$ & $3 \pm 0.2^{\star} \#$ \\
\hline Nigrospora sphaerica & $0.0 \pm 0.0$ & $0.0 \pm 0.0$ & $6.0 \pm 0.6^{\star} \#$ & $0.0 \pm 0.0$ & $6.0 \pm 0.2^{*} \#$ & $3.5 \pm 0.0^{*} \#$ \\
\hline Paraconiothyrium brasiliense & $0.0 \pm 0.0$ & $0.0 \pm 0.0$ & $5.0 \pm 0.3^{*} \#$ & $0.0 \pm 0.0$ & $4.0 \pm 0.0^{*} \#$ & $4.0 \pm 0.0^{*} \#$ \\
\hline Penicillium afellutanum & $3.0 \pm 0.2$ & $3.0 \pm 0.2$ & $6.0 \pm 0.6^{\star} \#$ & $0.0 \pm 0.0^{\star} \#$ & $2.0 \pm 0.5^{\star} \#$ & $5.0 \pm 0.2^{\star} \#$ \\
\hline Penicillium expansum & $2.0 \pm 0.2$ & $5.0 \pm 0.2$ & $3.0 \pm 0.2^{\star} \#$ & $0.0 \pm 0.0^{\star} \#$ & $4.0 \pm 0.0^{*} \#$ & $5.5 \pm 0.5^{\star} \#$ \\
\hline Penicillium olsonii & $1.5 \pm 0.3$ & $3.5 \pm 0.3$ & $1.0 \pm 0.2^{*} \#$ & $0.0 \pm 0.0^{*} \#$ & $1.5 \pm 0.2 \#$ & $3.0 \pm 0.6^{\star} \#$ \\
\hline Rosellinia corticium & $2.0 \pm 0.2$ & $4.5 \pm 0.3$ & $7.0 \pm 0.6^{\star} \#$ & $0.0 \pm 0.0^{*} \#$ & $3.0 \pm 0.2^{*} \#$ & $7.0 \pm 0.2^{*} \#$ \\
\hline
\end{tabular}

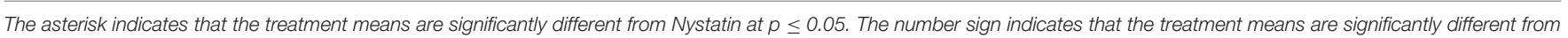
Amphotericin $B$ at $p \leq 0.05$

accession numbers for strains 1D6, 3H9, 4G12, and 4G4 using $23 \mathrm{~S}$ rDNA are KM387727, KM387728, KM387729, and KM387730, respectively. Phylogenetic tree data suggested that that the three Paenibacillus strains are P. polymxa (Figure 2B), and further suggested that strain $4 \mathrm{G} 4$ is different than 1D6 and $3 \mathrm{H} 9$.

\section{Scanning Electron Microscope (SEM) Imaging of Endophytes}

Scanning electron microscopy was used to visualize the external appearance of the candidate endophytes (Figure 3). Of the three strains predicted to be P. polymxa, strain 1D6 was an elongated rod with an apparent smooth surface; strain $3 \mathrm{H} 9$ was an elongated rod with a rough surface; while strain $4 \mathrm{G} 4$ was a cylindrical rod with an apparently rough surface. The Citrobacter-predicted strain 4G12 had a rhomboidal hexagonal rod phenotype.

\section{In vitro Interaction between Each Endophyte and F. graminearum}

To better understand the anti-fungal mode of action of the candidate endophytes, the in vitro interactions between $F$. graminearum and each endophyte were visualized following their co-incubation on a microscope slide and subsequent staining with the vitality stains, neutral red and Evans blue. All the four endophytes caused apparent dramatic breakage of F. graminearum hyphae when compared to the control zone on the other side of the microscope slide (that was exposed to only LB media) (Figure 4). Upon staining with Evans blue (which stains dead cells in blue), fungal hyphae in contact with the commercial biological control or each of the four endophytes stained blue (Figures 5A,C,E,G,I) compared to the buffer controls (Figures 5B,D,F,H,J), suggesting that hyphae in contact with each bacterial endophyte died. Combined, these results suggest that all four endophytes have fungicidal activity.

\section{Candidate Fungicide Mechanism of Action}

A candidate gene approach was undertaken to help understand the fungicide mode of action of the endophytes. Paenibacillus are well known to produce fusaricidin compounds that combat various fungal pathogens including F. graminearum; the compound is in fact named after Fusarium (Kajimura and Kaneda, 1996, 1997; Beatty and Jensen, 2002; Choi et al., 2008). To detect the presence of fusaricidin biosynthetic genes in the three predicted Paenibacillus strains, PCR primers were designed based on the fusaricidin synthase gene sequence (GenBank accession \# EU184010). Each genome amplified a single band that was sequenced; the results revealed that all three of the Paenibacillus endophyte genomes encode a putative fusA ortholog, with DNA sequence identities ranging from 92 to $94 \%$ (Figure 6A, Table S2). GenBank accession numbers for fusA sequences amplified from strains 1D6, 3H9, $4 \mathrm{G} 4$ were KT343965, KT343966, and KT343967, respectively. FusA is a non-ribosomal peptide synthetase with relaxed substrate 

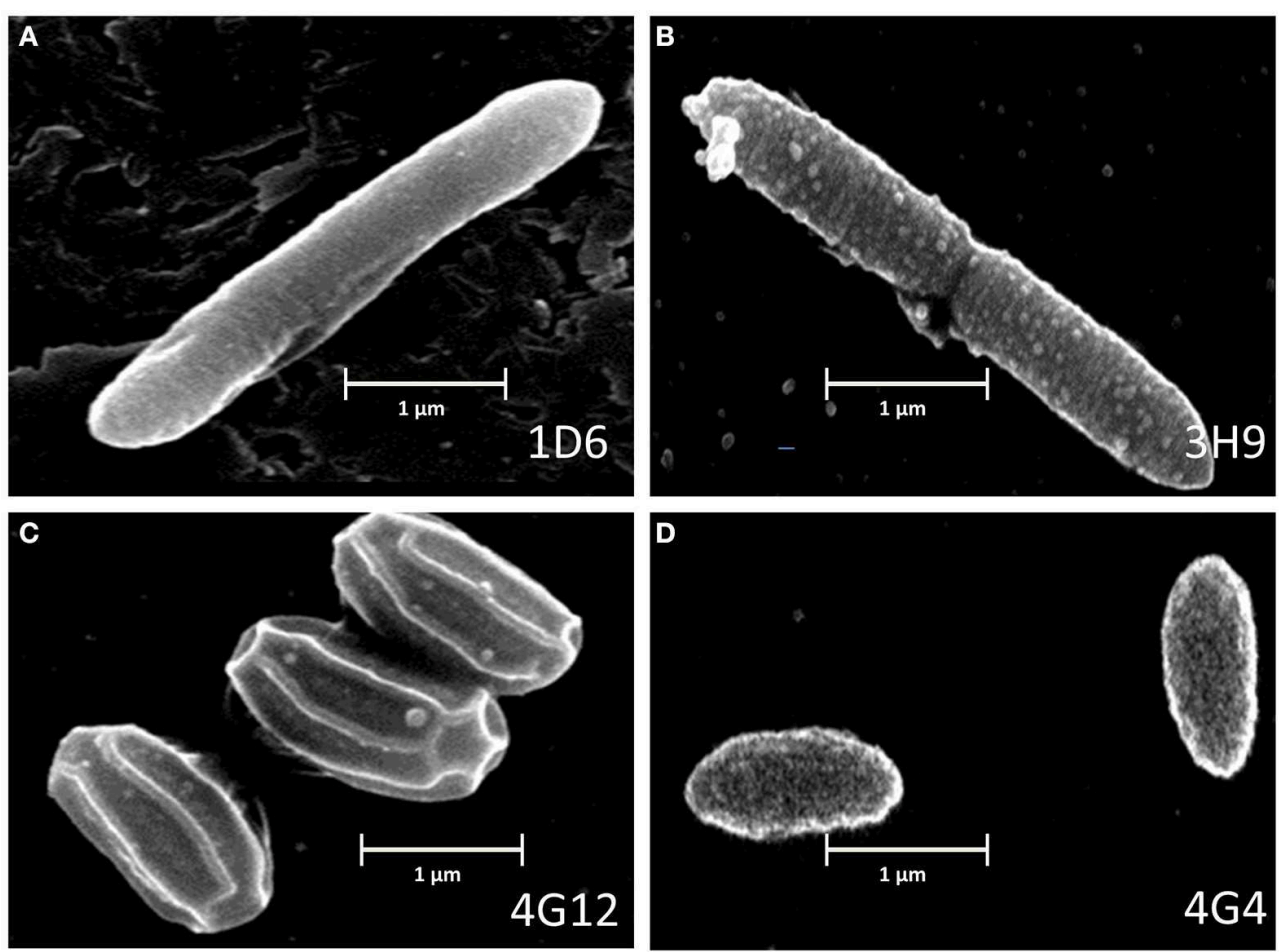

FIGURE 3 | Electron microscope images of the anti-fungal endophyte strains. (A-D) correspond to strains 1D6, 3H9, 4G12, and 4G4, respectively.

specificity that can incorporate different amino acids, resulting in different fusaricidin derivatives (Han et al., 2012). To confirm that the fusA orthologs were expressed by the endophytes, and to identify the specific fusaricidin derivatives produced, LC/MS was employed. Peaks with $\mathrm{M}+\mathrm{Z}$ similar to fusaricidin $\mathrm{C}$ (947.6), fusaricidin B (883), and fusaricidin D (961.7) were detected in the liquid cultures of strains $1 \mathrm{D} 6,3 \mathrm{H} 9$, and $4 \mathrm{G} 4$, respectively (Figures 6B-D) (Kajimura and Kaneda, 1996, 1997; Beatty and Jensen, 2002). Combined, these results demonstrate that the well-known anti-Fusarium compound fusaricidin is encoded and expressed by each of the three Paenibacillus endophytes.

\section{Suppression of Gibberella Ear Rot (GER) in Planta}

Greenhouse experiments were undertaken to determine if the endophytes could suppress Gibberella ear rot (GER) in planta using a modern maize hybrid, P35F40, which is susceptible to this disease. To confirm that the candidate bacterial strains originally isolated from the two evolutionarily distant maize genotypes $(Z$. diploperennis and Parviglumis) could colonize the internal tissues of this modern hybrid, thus behaving as endophytes, GFP tagging was conducted. Attempts were made to GFP tag all endophytes, but unfortunately, only strain 4G12 from ancestral Parviglumis, was successfully tagged. GFP-tagged 4G12 was visualized by scanning confocal microscopy and shown to colonize maize roots (Figures 7A,B), confirming its behavior as an endophyte in the modern maize relative. All four endophytes were then tested for their ability to suppress GER under greenhouse conditions in two independent trials (Figures 7,8). The main entrance routes for
F. graminearum in maize are exposed silks where the ascospores can germinate and grow toward the developing ear (Sutton, 1982; Kebebe et al., 2015). Therefore, the disease severity was scored as the length of diseased area, measured from the ear tip where Fusarium spores were introduced, relative to the total length of the ear (Figure 7I). Kernel yields were also quantified:

\section{First Greenhouse Trial (Summer 2012)}

Representative pictures of treated ears are shown (Figures 7C-H). Treatment with three of the four endophytes caused significant reductions $(P \leq 0.05)$ in GER disease severity ranging from 12 to $38 \%$ : strain 1 D6 resulted in the greatest disease suppression followed by strain $4 \mathrm{G} 12$ and then strain $4 \mathrm{G} 4$, while the effect of strain $3 \mathrm{H} 9$ on GER suppression was statistically insignificant when compared to the Fusarium treatment only, at $P<0.05$ (Figure 7J, Table 2). None of the endophyte treatments caused a significant change in grain yield, at $P \leq 0.05$ (Figure 7K, Table 2).

\section{Second Greenhouse Trial (Summer 2013)}

In the second trial, the disease pressure was increased by raising the humidity. Representative pictures of treated ears are shown (Figures 8A-F). Treatments with all four of the endophytes caused significant reductions $(P \leq 0.05)$ in GER disease severity ranging from 59 to $84 \%$ : strains $1 \mathrm{D} 6,4 \mathrm{G} 12$, and $4 \mathrm{G} 4$ resulted in the statistically greatest disease suppression, while again the effect of strain 3H9 on GER suppression was the lowest, but this time statistically significant compared to the Fusarium treatment only, 
A
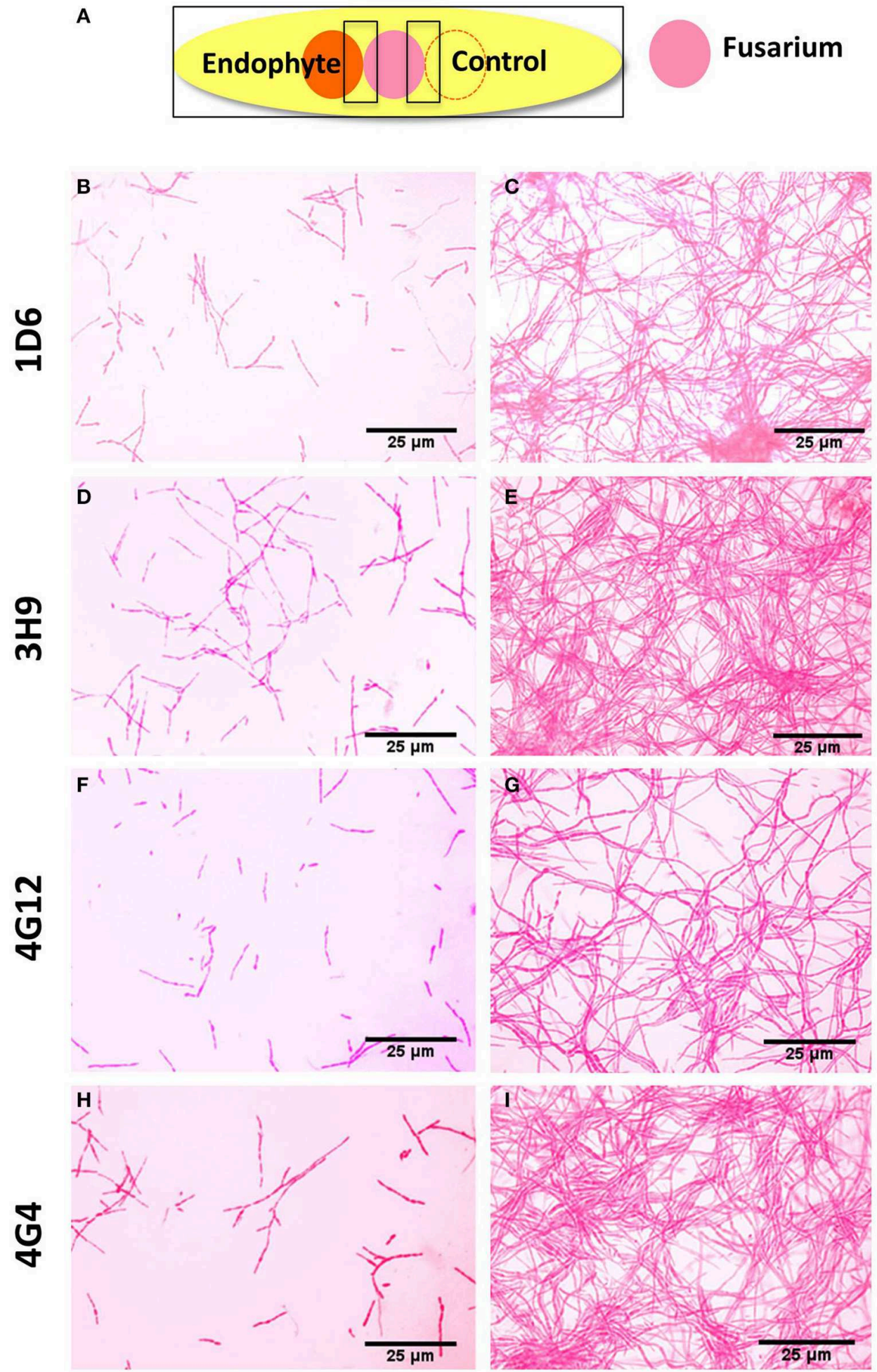

FIGURE 4 | Microscopic in vitro interactions between each anti-fungal endophyte and $\boldsymbol{F}$. graminearum. (A) Cartoon of the experimental methodology to examine microscopic in vitro interactions between F. graminearum (pink) and each endophyte (orange) or the buffer control (LB medium). The microscope slides were pre-coated with PDA and incubated for $24 \mathrm{~h}$. F. graminearum hyphae were then stained with neutral red. Shown are representative microscope slide pictures $(n=3)$ of the interactions between F. graminearum and: (B) Strain 1D6 compared to (C) the buffer control; (D) Strain 3H9 compared to (E) the buffer control; (F) Strain 4G12 compared to (G) the buffer control; (H) Strain 4G4 compared to (I) the buffer control. 


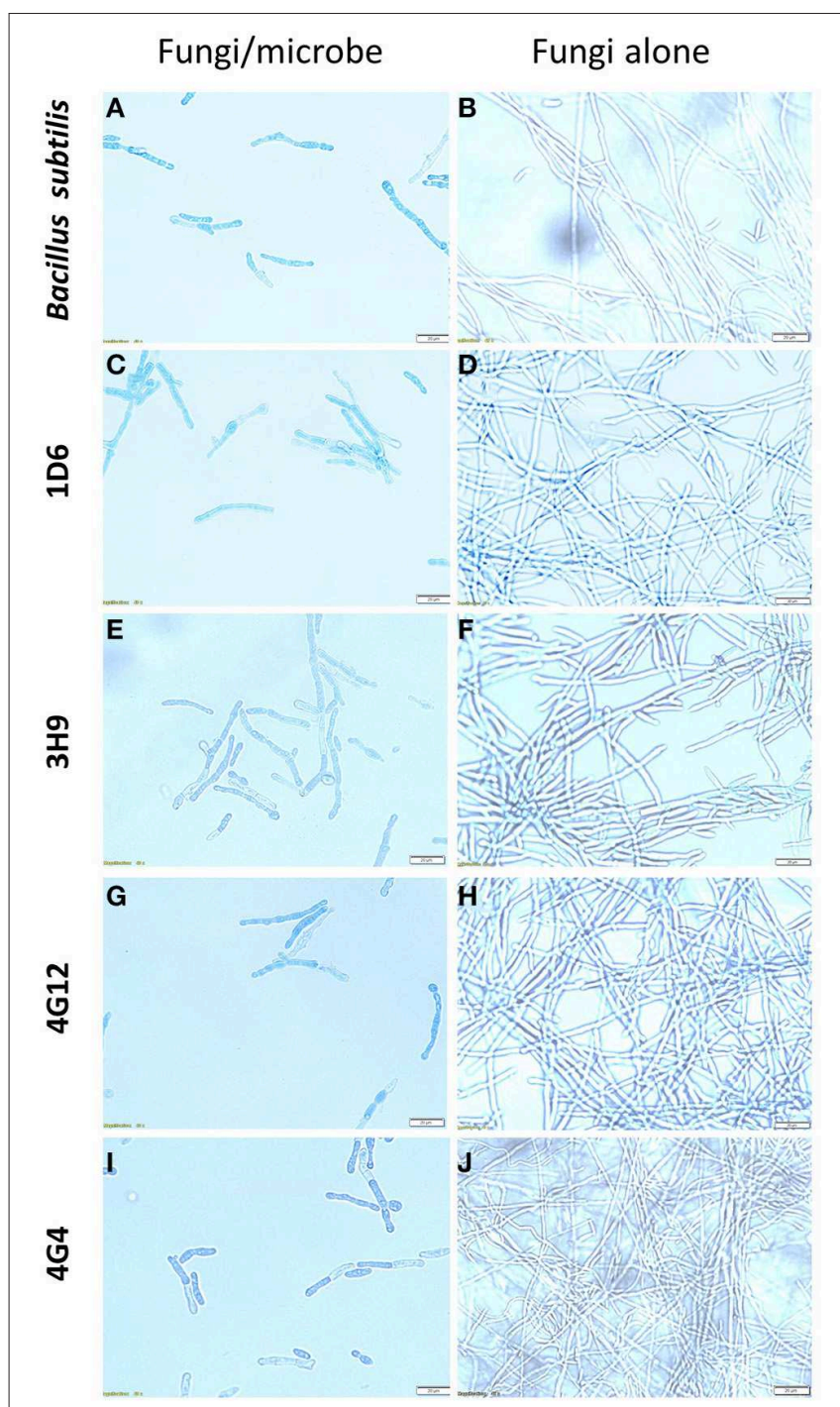

FIGURE 5 | The effects of the candidate endophytes on $F$. graminearum in vitro using the vitality stain, Evans blue. Shown are representative microscope slide pictures $(n=3)$ of the interactions of $F$. graminearum with: (A) the commercial biological control agent, Bacillus subtilis (100 mg/10 ml) compared to (B) the buffer control; (C) Strain 1D6 compared to (D) the buffer control; (E) strain 3H9 compared to (F) the buffer control; (G) Strain 4G12 compared to $\mathbf{( H )}$ the buffer control; (I) Strain 4G4 compared to (J) the buffer control.

at $P<0.05$ (Figure $\mathbf{8 H}$, Table 3 ). All of the endophyte treatments caused dramatic 3-4-fold increases in grain yield compared to the Fusarium treatment only (Figure 8I, Table 2).

\section{Effect of the Endophyte Treatments on DON Contamination}

In order to quantify DON levels in maize seeds, ELISA-based testing was conducted. Immediately after harvest, only traces of DON were detected in plants treated with Fusarium only (approximately $0.1 \mathrm{ppm}$ ) while all other treatments did not show any detectable levels of DON (data not shown). Seeds were stored at room temperature inside closed envelopes for one year, then the samples were analyzed again for DON content. Consistently in both trials, all four endophyte treatments caused dramatic reductions in DON accumulation during storage, with DON levels declining from approximately $3.5 \mathrm{ppm}$ to $0.1-1.0 \mathrm{ppm}$ (Figure 9, Table 3). The majority of the endophyte treatments resulted in a DON content of only $0.1 \mathrm{ppm}$, equivalent to a $97 \%$ reduction compared to the Fusarium-only control.

\section{DON Detoxification}

In order to test the ability of the candidate endophytes to directly detoxify DON into epi-DON in vitro, a standard HPLC based method was used. However, the results revealed that none of the candidate endophytes could directly detoxify DON into epiDON (Figure S1).

\section{Discussion}

We hypothesized that the wild relatives of modern crops, which grow without fungicides, may host beneficial endophytes that help their hosts to naturally combat fungal pathogens including F. graminearum. In this study we found support for this hypothesis. In vitro screening of 215 maize bacterial endophytes (Figures 1A,B) identified four candidate endophytes that could inhibit the growth of F. graminearum and its DON mycotoxin to within the acceptable levels (Figure 9). Despite the screen containing 116 endophytes from non-wild maize genotypes (45 from modern maize and 71 from traditional landraces, totaling $54 \%$ of the library), the three most potent endophytes were isolated from their wild counterparts (representing $46 \%$ of the endophytes screened) (Figures 1, 7, 8). Specifically, antiFusarium endophyte strain 1D6 was originally isolated from $Z$. diploperennis, and strains $4 \mathrm{G} 12$ and 4G4 were isolated from Parviglumis (Figure 2A). The remaining candidate endophyte (strain 3H9) was isolated from a modern maize variety $(Z$. mays ssp. mays, Pioneer 3751 hybrid). The suggested mode of action of all four endophytes was fungicidal, not fungistatic (Figures 4, 5). Plants treated with these endophytes showed a remarkable reduction in DON contamination during storage (Figure 9) which might be attributed to an initial reduction in F. graminearum inoculum, as none of the endophytes were able to directly inactivate DON in vitro (Figure S1). The permitted level of DON mycotoxin contamination in maize grain is $2 \mathrm{ppm}$ in food and 5 ppm in animal feed (Jelinek et al., 1988). However, the dietary value permitted for swine feed in Canada and the USA is only 1 ppm (Schaafsma et al., 2009). Except for strain 3H9, the endophytes consistently reduced DON to within the $1 \mathrm{ppm}$ level during storage.

\section{Host Environmental History}

Interestingly, the anti-Fusarium endophytes isolated from the wild teosintes (1D6, 4G12, and 4G4) showed an exceptionally broad spectrum of anti-fungal activities (Table 1). Parviglumis teosinte appears to have been adapted for thousands of years in the seasonal tropical forest region of the Central Balsas Valley of southwestern Mexico (Piperno et al., 2009). Zea diploperennis originated from the Sierra de Manantlan region of Jalisco, in 
A

\begin{tabular}{|c|c|c|}
\hline Strain & \% Identity to fusA & E-value \\
\hline 1D6 & $92 \%$ & $1 \mathrm{e}-64$ \\
\hline $3 \mathrm{H} 9$ & $93 \%$ & $7 \mathrm{e}-62$ \\
\hline 4G4 & $94 \%$ & $1 \mathrm{e}-63$ \\
\hline
\end{tabular}

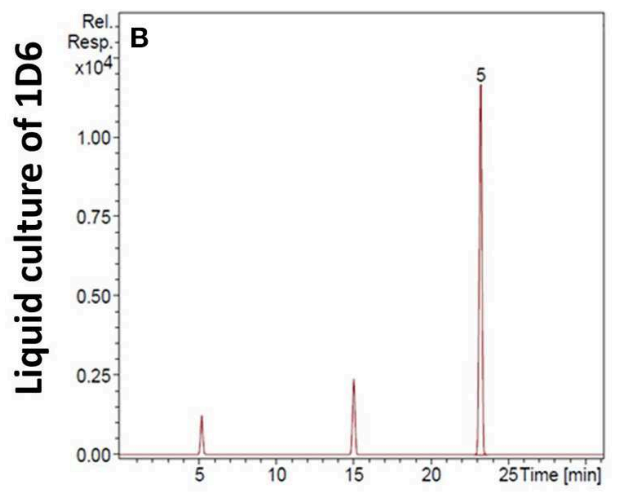

Mass spectrum
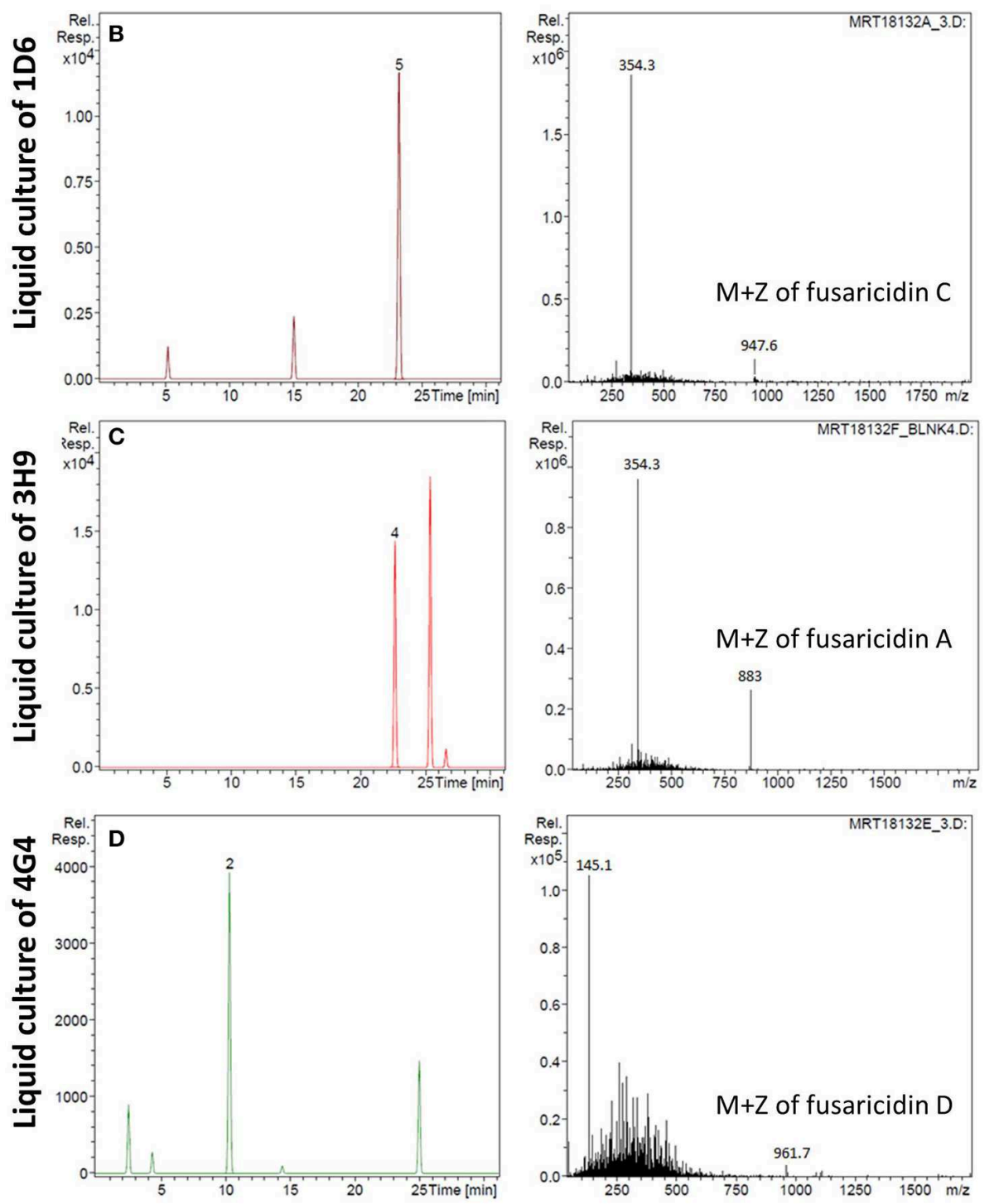

FIGURE 6 | Molecular and biochemical detection of the candidate anti-fungal compound, fusaricidin, in Paenibacillus strains. (A) Details of fusA gene orthologs isolated from the candidate Paenibacillus endophytes by PCR amplification. (B-D) Combined ion chromatogram/mass spectrum for candidate fusaricidin derivatives detected in the cultures of the Penibacillus endophytes as indicated. 

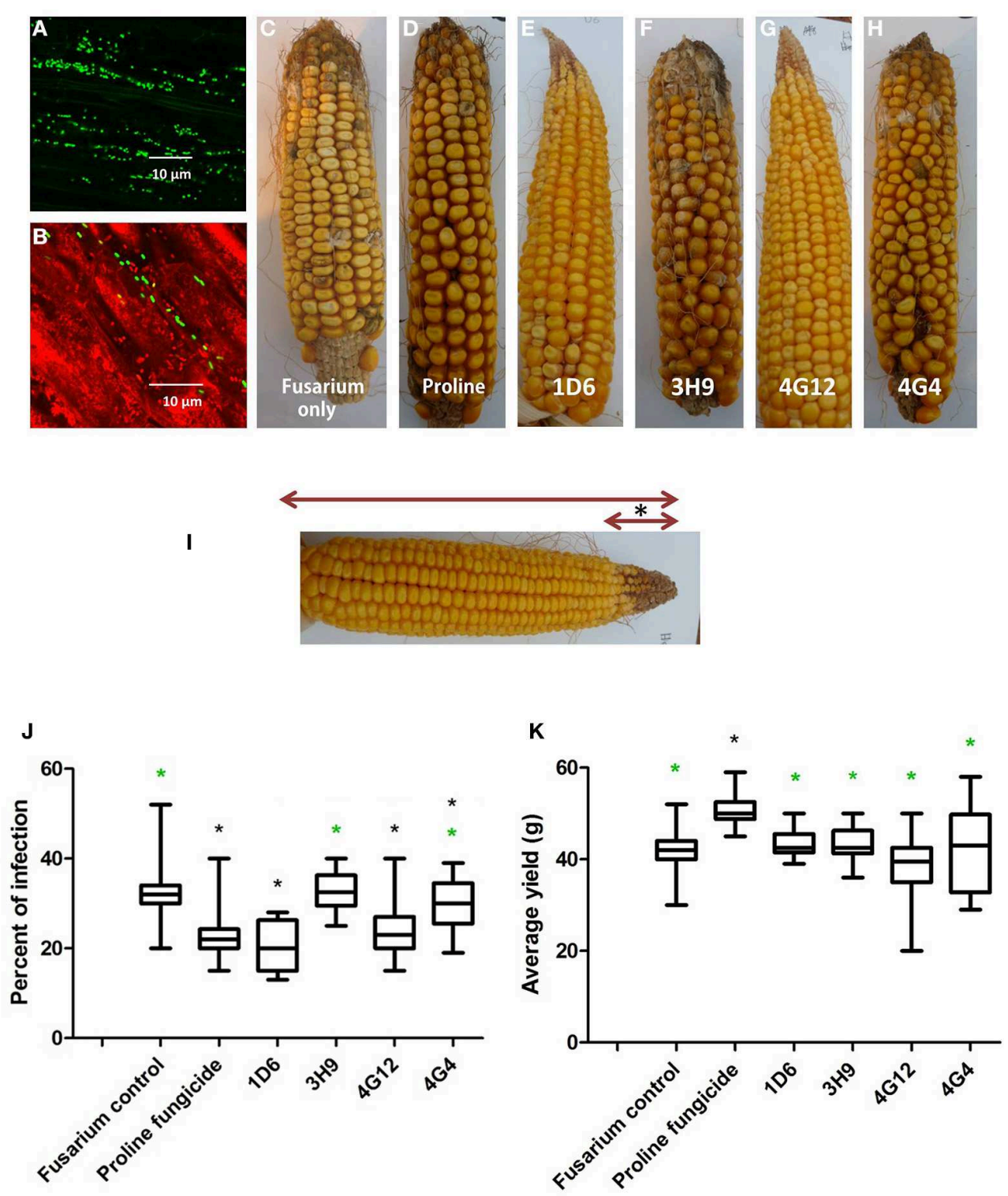

FIGURE 7 | Greenhouse trial 1 to test for the ability of the candidate endophytes to suppress Gibberella Ear Rot (GER) in a modern hybrid.

(A,B) GFP-tagged endophyte strain 4G12 visualized inside maize roots, in the (A) absence or (B) presence of propidium iodide that outlines the cell with red color. (C-H) Representative ears from each treatment. (I) Picture of an ear to illustrate the methodology of scoring disease severity: The fungal pathogen was introduced to the tip of the ear, indicated by the asterisk. Therefore, the disease was scored as the ratio of the length of the diseased ear tip portion relative to total ear length, multiplied by 100 to give a percentage. (J, K) Quantification of the effect of different treatments on GER suppression, as: (J) percent ear infection, and (K) average grain yield per plant. For both measurements, $n=20$ per treatment $(n=10$ for both controls). The whiskers indicate the range of data points. The black asterisk indicates that the treatment means were significantly different from the Fusarium only treatment at $p \leq 0.05$. The green asterisk indicates that the treatment means were significantly different from prothioconazole fungicide (Proline) treatment at $p \leq 0.05$.

Southern Mexico, which has both dry and wet climates but with very high levels of total rainfall $(1700 \mathrm{~mm})$ (Iltis and Doebley, 1980; Sánchez-Velásquez et al., 2002). Perhaps the broad spectrum activity of the endophytes from these Zea genotypes is the result of co-evolutionary selection by their host plants for endophytes that could combat fungal pathogens which are especially problematic in regions of high humidity. In contrast, the candidate endophyte (strain 3H9) isolated from the modern hybrid, which was bred under temperate conditions, showed the weakest anti-Fusarium activities (Figures 1D, 7J, 8H, 9A) as well as the narrowest target spectrum of anti-fungal activity (Table 1).

Unfortunately, there has been no systematic comparison of fungal resistance in teosintes vs. modern maize, though one Fusarium species (Gibberella fujikori) has been reported to infect both (Lange et al., 2014). In a survey concerning the incidence of Fusarium species in maize seeds worldwide, Fusarium species 

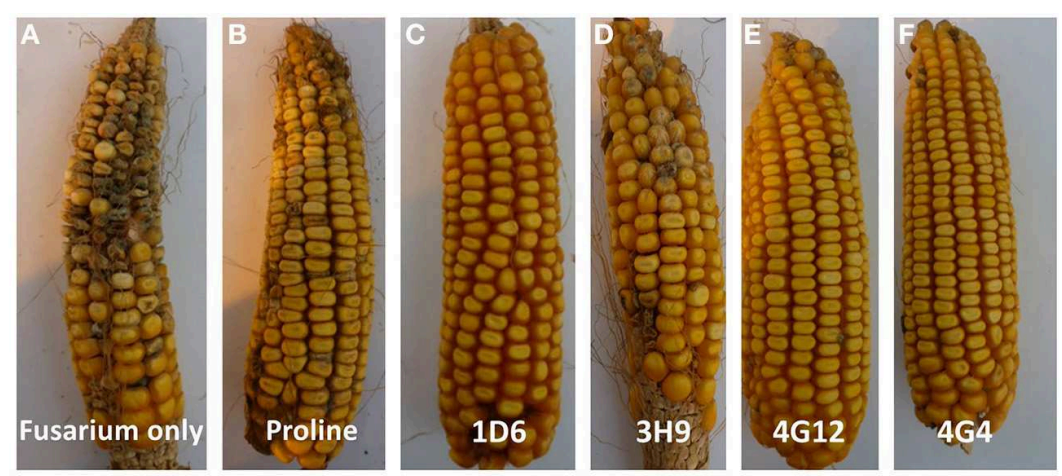

G
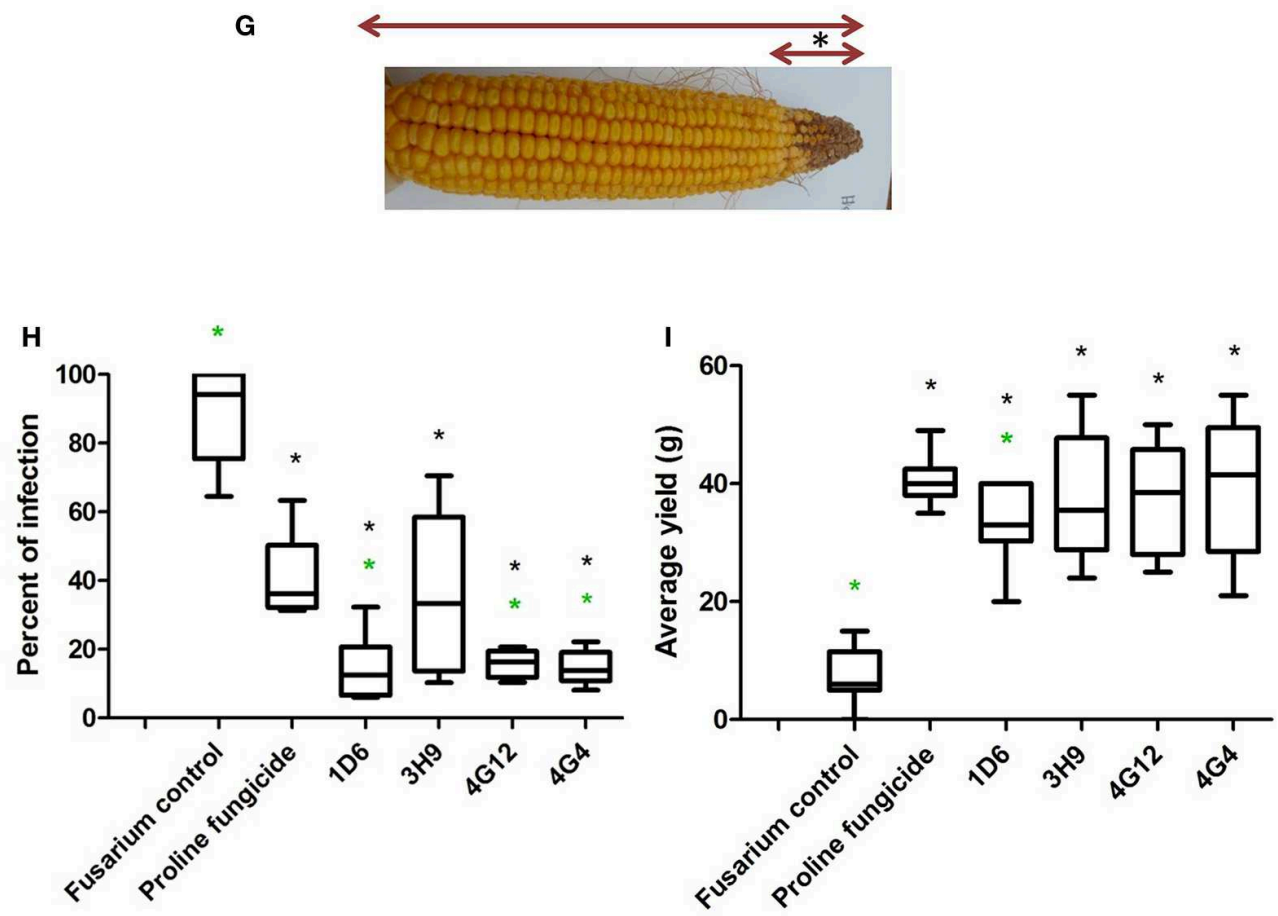

FIGURE 8 | Greenhouse trial 2 to test for the ability of the candidate endophytes to suppress Gibberella Ear Rot in a modern hybrid.

(A-F) Representative ears from each treatment. (G) Picture of an ear to illustrate the methodology of scoring disease severity: the fungal pathogen was introduced to the tip of the ear, indicated by the asterisk. Therefore, the disease was scored as the ratio of the length of the diseased ear tip portion relative to total ear length, multiplied by 100 to give a percentage. (H, I) Quantification of the effect of different treatments on GER suppression, as (H) percent ear infection, and (I) average grain yield per plant. For both measurements, $n=20$ per treatment ( $n=10$ for both controls). The whiskers indicate the range of data points. The black asterisk indicates that the treatment means were significantly different from the Fusarium only treatment at $p \leq 0.05$. The green asterisk indicates that the treatment means were significantly different from prothioconazole fungicide (Proline) treatment at $p \leq 0.05$.

were the most abundant fungi detected (39-62\%) with the most frequent species being F. moniliforme (MacDonald and Chapman, 1997). Fusarium species were reported in 10\% of wild teosinte seeds collected from Mexico, Nicaragua and Guatemala, with $F$. moniliforme and F. subglutinans reported to be the most abundant (Desjardins et al., 2000). However, the authors noted that whereas Fusarium species were detected in $100 \%$ of modern maize seeds ( $Z$. mays spp. mays), their incidence in teosinte seeds was only $4 \%$ when grown under the same conditions, and in general, at least anecdotally, teosintes appeared to have much lower rates of Fusarium infection than modern maize in Mexico (Desjardins et al., 2000). It may be that there has been three-way co-evolutionary selection within the teosintes between the host plant, its endophytes and Fusarium species.

\section{Host Life Strategy}

This study involved Zea genotypes which encompassed three critical life strategy transitions: (1) the evolutionary transition from wild perennial to annual growth habit; (2) the agricultural transition from wild to domesticated primitive plant; and (3) 
TABLE 2 | Suppression of Gibberella Ear Rot by the candidate endophytes in two replicate greenhouse trials.

\begin{tabular}{|c|c|c|c|c|}
\hline Treatment & $\begin{array}{l}\% \text { infection } \\
\text { (mean } \pm \\
\text { SEM) }{ }^{*}\end{array}$ & $\begin{array}{l}\% \text { disease } \\
\text { reduction } \\
\text { relative to } \\
\text { Fusarium only } \\
\text { treatment }\end{array}$ & $\begin{array}{l}\text { Average yield } \\
\text { per plant }(\mathbf{g})^{\star}\end{array}$ & $\begin{array}{c}\% \text { yield } \\
\text { increase } \\
\text { relative to } \\
\text { Fusarium only } \\
\text { treatment }\end{array}$ \\
\hline \multicolumn{5}{|c|}{ GREENHOUSE TRIAL 1} \\
\hline Fusarium only & $33.7 \pm 2.3 \mathrm{a}$ & 0.0 & $41.7 \pm 1.3 \mathrm{a}$ & 0.0 \\
\hline $\begin{array}{l}\text { Proline } \\
\text { fungicide }\end{array}$ & $23.1 \pm 2.0 \mathrm{~b}$ & 31.5 & $50.9 \pm 1.2 b$ & 22 \\
\hline $1 \mathrm{D} 6$ & $20.9 \pm 1.7 b$ & 38 & $43.5 \pm 1.2 \mathrm{a}$ & 4.3 \\
\hline $3 \mathrm{H} 9$ & $32.4 \pm 1.4 \mathrm{a}$ & 3.9 & $43.1 \pm 1.3 \mathrm{a}$ & 3.4 \\
\hline $4 \mathrm{G} 12$ & $24.1 \pm 2.1 b$ & 28.5 & $38.3 \pm 2.5 a$ & -8.2 \\
\hline 4G4 & $29.7 \pm 1.7 d$ & 11.9 & $42.5 \pm 2.9 a$ & 1.9 \\
\hline \multicolumn{5}{|c|}{ GREENHOUSE TRIAL 2} \\
\hline Fusarium only & $88.5 \pm 3.8 \mathrm{a}$ & 0.0 & $7.7 \pm 1.2 \mathrm{a}$ & 0.0 \\
\hline $\begin{array}{l}\text { Proline } \\
\text { fungicide }\end{array}$ & $41.4 \pm 4.5 b$ & 53.2 & $40.8 \pm 1.2 b$ & 429.9 \\
\hline $1 \mathrm{D} 6$ & $14.6 \pm 1.9 \mathrm{c}$ & 83.5 & $33.5 \pm 2.1 \mathrm{c}$ & 335 \\
\hline $3 \mathrm{H} 9$ & $36.1 \pm 6.2 b$ & 59.2 & $37.5 \pm 3.3 b$ & 387 \\
\hline $4 \mathrm{G} 12$ & $16 \pm 1.1 \mathrm{c}$ & 81.9 & $37.4 \pm 3.2 b$ & 385.7 \\
\hline 4G4 & $14.6 \pm 1.3 c$ & 83.5 & $39.8 \pm 3.0 b$ & 416.9 \\
\hline
\end{tabular}

*Letters that are different from one another indicate that their means are statistically different $(P \leq 0.05)$.

the transition from a domesticated primitive plant to modern cultivars (Rosenthal and Dirzo, 1997; Dávila-Flores et al., 2013). As noted above, the three consistently robust anti-fungal endophytes were isolated from $Z$. diploperennis, which is a wild perennial teosinte, and from Parviglumis, which is a wild annual teosinte. These two Zea genotypes were previously shown to be more resistant to insects compared to domesticated modern maize (an annual), with $Z$. diploperennis showing more resistance than Parviglumis (Rosenthal and Dirzo, 1997; Dávila-Flores et al., 2013). These results are consistent with other reports that domestication reduces resistance to insects (Lange et al., 2014) and herbivores (Chen et al., 2015). To explain these results, Rosenthal and Dirzo (1997) suggested the resource allocation hypothesis in which metabolic resources are diverted away from plant defense as a result of selection for faster plant growth rates (associated with annualism) and higher grain yields (associated with domestication and breeding). This hypothesis is supported by results from other crops (Benrey et al., 1998; Gols et al., 2008). Given the results of this study, it is interesting to pose a parallel hypothesis: as plants diverted precursors for defense compounds to enable faster plant growth and higher grain yield, they may have also prevented their endophytes from producing defense compounds, thus reducing the reasons to support such endophytes. Modern breeding under conditions of fungicide inputs may have also caused crops to no longer devote metabolic resources to support endophytes with redundant pesticide function. Alternatively, it may be that selection by humans against plant-derived toxins during domestication and breeding may have also involved selection against anti-pathogen
TABLE 3 | Reduction of DON mycotoxin accumulation during storage following treatment with the candidate endophytes.

\begin{tabular}{lcc}
\hline Treatment & $\begin{array}{c}\text { DON content (ppm) } \\
\text { (mean } \pm \text { SEM) }^{*}\end{array}$ & $\begin{array}{c}\text { \% of DON reduction relative } \\
\text { to Fusarium }\end{array}$ \\
\hline GREENH treatment
\end{tabular}

*Letters that are different from one another indicate that their means are statistically different $(P \leq 0.05)$.

endophytes with indiscriminate toxicity, by altering plant loci that promote the colonization of specific endophytes. These three hypotheses (host-endophyte resource allocation hypothesis, pesticide-endophyte-redundancy hypothesis, endophyte-toxinselection hypothesis) require further investigation. As this study involved only two modern maize genotypes (B73, Pioneer 3751) focusing on only a single pathogen, future studies should involve a more balanced number of plant genotypes across the evolutionary spectrum.

\section{Paenibacillus polymyxa Strains Span the Evolutionary Transitions of Zea}

In this study, despite testing 215 diverse bacterial endophyte strains, three out of four candidate endophytes with antiFusarium activity were predicted to be Paenibacillus polymyxa (strains 1D6, 3H9, and 4G4) with a fourth strain identified as a Citrobacter sp. (strain 4G12) (Figure 2, Table S1). The three $P$. polymyxa appear to be distinct, when all the data are taken into account [16S rDNA phylogenetic tree data (Figure 2B), fus A gene sequence information (Figure 6A, Table S2), biochemical profiles (Figure 6), and anti-Fusarium results (e.g., Figure 7)]. Bacterial endophytes previously isolated from different maize varieties belong to diverse genotypes including Paenibacillus and Citrobacter, but also Bacillus, Clostridium, Enterobacter, Pantoea, Methylobacteria, Pseudomonas, Burkholderia, Erwinia, and Microbacterium (Johnston-Monje and Raizada, 2011; Cotta et al., 2014; Johnston-Monje et al., 2014).

As already noted, the putative $P$. polymyxa endophytes appear to span hundreds of thousands of years of evolutionary transitions of Zea (Matsuoka et al., 2002), since they were present in a wild Mexican perennial (Z. diploperennis), a wild Mexican annual (Parviglumis) and a modern temperate hybrid (Pioneer 3751) (Table 2). Therefore, these anti-Fusarium Paenibacilli cross host boundaries of evolution, domestication, migration 

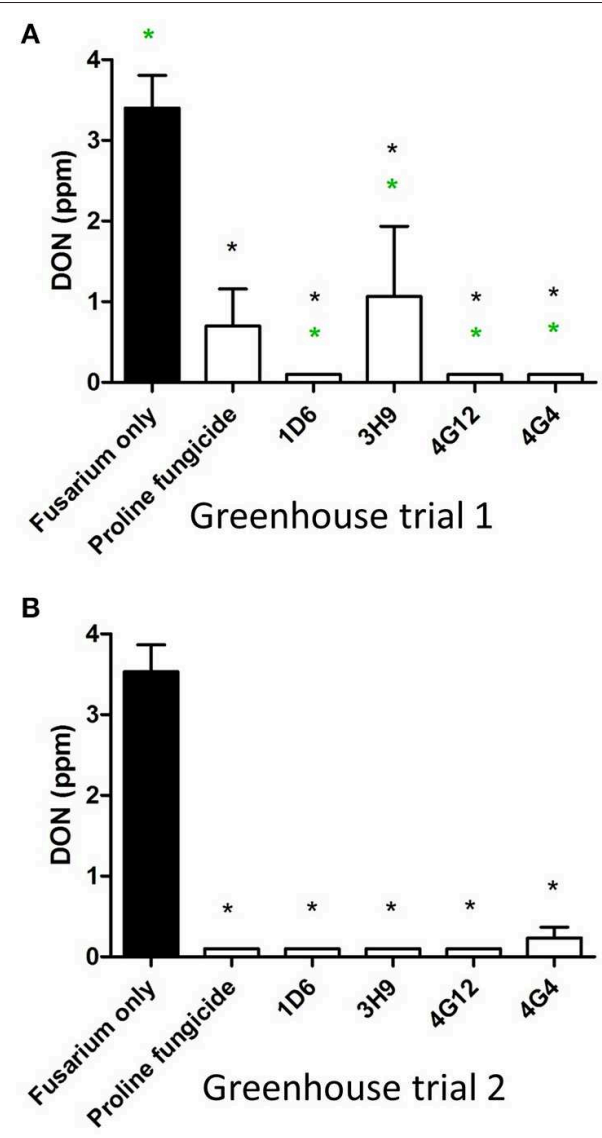

FIGURE 9 | Test for the ability of the candidate endophytes to reduce DON mycotoxin accumulation in maize grain during storage. DON measurements after storage of maize grain from: (A) greenhouse trial 1 (summer 2012), and (B) greenhouse trial 2 (summer 2013). For both trials, $n=3$ pools of seeds. The black asterisk indicates that the treatment means were significantly different from the Fusarium only treatment at $p \leq 0.05$. The green asterisk indicates that the treatment means were significantly different from the prothioconazole fungicide (Proline) treatment at $p \leq 0.05$.

and breeding, suggesting a tight conserved host-endophyte relationship. Consistent with this observation, $P$. polymyxa was previously reported as a ubiquitous, conserved endophyte across diverse Zea genotypes including wild perennial and annual teosintes, traditional farmer landraces and modern genotypes (Johnston-Monje and Raizada, 2011). P. polymyxa is well known as a good plant colonizer, which is in part due to its robust ability to form biofilms (Timmusk et al., 2005; Haggag and Timmusk, 2008). Furthermore, consistent with our results, $P$. polymyxa was previously reported to antagonize numerous plant pathogens (Timmusk et al., 2009; Xu and Kim, 2014) including F. graminearum (He et al., 2009). P. polymyxa was further shown to decrease DON production under greenhouse conditions ( $\mathrm{He}$ et al., 2009), consistent with the results of this study.

Previous reports have shown that the anti-fungal mechanism of action of Paenibacillus sp. involves production of potent antifungal compounds including polymyxins, fusaricidins, colistins, volatiles, and lytic enzymes (He et al., 2007; Raza et al., 2008, 2009, 2015; Naghmouchi et al., 2012). In particular, Paenibacillus is well-known to combat $F$. graminearum by employing fusaricidin, a compound named after Fusarium as noted earlier (Kajimura and Kaneda, 1996, 1997; Beatty and Jensen, 2002; Choi et al., 2008). Consistent with the literature, our results show that the three $P$. polymyxa strains characterized in this study produce fusaricidins (Figure 6, Table S2). However, we do not exclude other compounds as the genus Paenibacillus is well-known for its ability to produce an arsenal of antimicrobial compounds including polyketides and non-ribosomal peptides. Fusaricidin production, together with the in vitro microscopic interaction data (Figures 4, 5, 6), suggests a fungicidal mechanism of action. P. polymyxa has also been shown to induce systemic host resistance (Mei et al., 2014). P. polymyxa was also shown to alter plant metabolism by enhancing the production of flavonoids such as apigenin-7-Oglucoside (Schmidt et al., 2014) or reducing cinnamic acid in root exudates. These compounds suppress the development of pathogen conidia, thereby significantly reducing their ability to colonize plants (Ling et al., 2011). It will be useful to investigate if the predicted Paenibacilli endophytes from this study also employ these modes of action. It will also be useful to test whether these strains are resistant to fusaric acid, an antibiotic produced by Fusarium; resistance to this compound has been shown to be essential for effective biological control against Fusarium species (Bacon and Hinton, 2011).

\section{The Emerging Importance of Citrobacter sp.}

As already noted, the anti-Fusarium endophyte strain $4 \mathrm{G} 12$ is predicted to be a Citrobacter species (Figure 2). Citrobacter species were previously reported as endophytes of an ancient Mexican landrace (Nal Tel) and teosinte (e.g., Z. nicaraguensis) (Johnston-Monje and Raizada, 2011), in addition to other plants including Brazilian sugarcane (Magnani et al., 2013) and the legume tree, Conzattia multixora which is exclusively found in Guatemala and Mexico (Wang et al., 2006). Citrobacter species were claimed to moderately control some fungal plant pathogens such as Monilinia fructicola, the causal agent of brown rot in stone fruits (Janisiewicz et al., 2013). However, to the best of our knowledge, Citrobacter was not previously reported to effectively control Fusarium species, suggesting that this genus may have a wider spectrum of anti-fungal activity than previously thought (Table 1).

\section{Conclusions}

This study has identified candidate endophytes that could suppress the serious, toxigenic fungal pathogen F. graminearum in maize. The endophytes reduced DON mycotoxin concentrations during storage to levels significantly below acceptable safety thresholds, a promising result that requires field level validation for further practical applications. The most potent of the candidate strains were derived from wild teosinte genotypes including the ancestor of modern maize. Further bioprospecting of wild relatives of modern crops for beneficial microbes may open a promising avenue for biocontrol against the most devastating diseases afflicting modern agriculture. 
Teosintes are under threat from deforestation, urbanization, and cattle, and it is hoped that this study will assist in efforts to conserve these wild species. These results, combined with the literature, have led us to several host-endophyte hypotheses with respect to plant defense that require further investigation.

\section{Author Contributions}

WM conducted all experiments and analyzed all data, but was assisted by CS for the greenhouse trials, and VL who performed the DON quantification experiments. TZ designed the DON detoxification experiment. WM wrote the manuscript, and MR edited the manuscript. All authors read and approved the manuscript.

\section{Acknowledgments}

We thank Prof. A. Schaafsma (Ridgetown College, University of Guelph, Canada) for kindly providing maize hybrid seeds. We thank Gui-Ying Mei (Agriculture and Agrifood Canada) for assistance with the DON detoxification experiment. We thank Dr. Kirk Gren (McMaster University, Hamilton, Canada) for assistance with fusaricidin detection. We thank Marina Atalla for assistance in disease scoring. We thank Dylan Harding (Department of Plant Agriculture, University of Guelph) for

\section{References}

Anthony, R. M., Brown, T. J., and French, G. L. (2000). Rapid diagnosis of bacteremia by universal amplification of $23 \mathrm{~S}$ ribosomal DNA followed by hybridization to an oligonucleotide array. J. Clin. Microbiol. 38, 781-788.

Bacon, C. W., and Hinton, D. M. (2011). In planta reduction of maize seedling stalk lesions by the bacterial endophyte Bacillus mojavensis. Can. J. Microbiol. 57, 485-492. doi: 10.1139/w11-031

Beatty, P. H., and Jensen, S. E. (2002). Paenibacillus polymyxa produces fusaricidintype antifungal antibiotics active against Leptosphaeria maculans, the causative agent of blackleg disease of canola. Can. J. Microbiol. 48, 159-169. doi: $10.1139 /$ w02-002

Benrey, B., Callejas, A., Rios, L., Oyama, K., and Denno, R. F. (1998). The effects of domestication of Brassica and Phaseolus on the interaction between phytophagous insects and parasitoids. Biol. Control 11, 130-140. doi: 10.1006/bcon. 1997.0590

Calvin, N., and Hanawalt, P. (1988). High-efficiency transformation of bacterial cells by electroporation. J. Bacteriol. 170, 2796-2801.

Chen, Y. H., Gols, R., and Benrey, B. (2015). Crop domestication and its impact on naturally selected trophic interactions. Annu. Rev. Entomol. 60, 35-58. doi: 10.1146/annurev-ento-010814-020601

Choi, S.-K., Park, S.-Y., Kim, R., Lee, C.-H., Kim, J. F., and Park, S.-H. (2008). Identification and functional analysis of the fusaricidin biosynthetic gene of Paenibacillus polymyxa E681. Biochem. Biophys. Res. Commun. 365, 89-95. doi: 10.1016/j.bbrc.2007.10.147

Chulze, S., Palazzini, J., Torres, A., Barros, G., Ponsone, M., Geisen, R., et al. (2014). Biological control as a strategy to reduce the impact of mycotoxins in peanuts, grapes and cereals in Argentina. Food Addit. Contam. 32, 471-479. doi: 10.1080/19440049.2014.984245

Cotta, S. R., Voll, R. E., de Jurelevicius, D. A., Marques, J. M., and Seldin, L. (2014). Endophytic microbial community in two transgenic maize genotypes and in their near-isogenic non-transgenic maize genotype. BMC Microbiol. 14:332. doi: 10.1186/s12866-014-0332-1 helpful comments on the manuscript. WM was supported by generous scholarships from the Government of Egypt and the University of Guelph (International Graduate Student Scholarships, 2012, 2014). This research was supported by grants to MR by the Ontario Ministry of Agriculture and Food (OMAF 030031) and the Grain Farmers of Ontario (GFO 051921).

\section{Supplementary Material}

The Supplementary Material for this article can be found online at: http://journal.frontiersin.org/article/10.3389/fpls.2015. 00805

Figure S1 | Test for the ability of the candidate endophytes to detoxify DON in vitro. Shown are representative HPLC chromatograms showing that none of the endophyte treatments caused DON detoxification. Shown are treatments with: (A) the buffer control (LB media), (B) endophyte 1D6, (C) endophyte 3H9, (D) endophyte 4G12, and (E) endophyte 4G4.

Table S1 | Taxonomic classification of maize bacterial endophytes based on 16S rDNA and 23S rDNA sequences and BLAST analysis (corresponding to Table 1) (Excel file).

Table S2 | Sequences of fusA orthologs from Paenibacillus endophytic species identified in this study (corresponds to Figure 4A) (Excel file).

Table S3 | Origin of the endophytes screened in this study including the maize genotypes and tissues from which they were isolated, and the best BLAST matches to the GenBank database (Excel file).

Dávila-Flores, A. M., DeWitt, T. J., and Bernal, J. S. (2013). Facilitated by nature and agriculture: performance of a specialist herbivore improves with host-plant life history evolution, domestication, and breeding. Oecologia 173, 1425-1437. doi: 10.1007/s00442-013-2728-2

Dereeper, A., Audic, S., Claverie, J.-M., and Blanc, G. (2010). BLAST-EXPLORER helps you building datasets for phylogenetic analysis. BMC Evol. Biol. 10:8. doi: 10.1186/1471-2148-10-8

Dereeper, A., Guignon, V., Blanc, G., Audic, S., Buffet, S., Chevenet, F., et al. (2008). Phylogeny. fr: robust phylogenetic analysis for the non-specialist. Nucl. Acids Res. 36, 465-469. doi: 10.1093/nar/gkn180

Desjardins, A. E., Plattner, R. D., and Gordon, T. R. (2000). Gibberella fujikuroi mating population A and Fusarium subglutinans from teosinte species and maize from Mexico and Central America. Mycol. Res. 104, 865-872. doi: 10.1017/S0953756299002002

Edwards, S. G. (2004). Influence of agricultural practices on Fusarium infection of cereals and subsequent contamination of grain by trichothecene mycotoxins. Toxicol. Lett. 153, 29-35. doi: 10.1016/j.toxlet.2004.04.022

Eilenberg, J. (2006). "Concepts and visions of biological control," in An Ecological and Societal Approach to Biological Control, eds J. Eilenberg and H. M. T. Hokkanen (Dordrecht: Springer), 1-11.

Gaudin, A. C. M., McClymont, S. A., Holmes, B. M., Lyons, E., and Raizada, M. N. (2011). Novel temporal, fine-scale and growth variation phenotypes in roots of adult-stage maize (Zea mays L.) in response to low nitrogen stress. Plant Cell Environ. 34, 2122-2137. doi: 10.1111/j.1365-3040.2011.02409.x

Gols, R., Wagenaar, R., Bukovinszky, T., Dam, N. M. V., Dicke, M., Bullock, J. M., et al. (2008). Genetic variation in defense chemistry in wild cabbages affects herbivores and their endoparasitoids. Ecology 89, 1616-1626. doi: 10.1890/070873.1

Haggag, W., and Timmusk, S. (2008). Colonization of peanut roots by biofilmforming Paenibacillus polymyxa initiates biocontrol against crown rot disease. J. Appl. Microbiol. 104, 961-969. doi: 10.1111/j.1365-2672.2007.03611.x

Han, J. W., Kim, E. Y., Lee, J. M., Kim, Y. S., Bang, E., and Kim, B. S. (2012). Site-directed modification of the adenylation domain of the fusaricidin 
nonribosomal peptide synthetase for enhanced production of fusaricidin analogs. Biotechnol. Lett. 34, 1327-1334. doi: 10.1007/s10529-012-0913-8

Hassan, Y. I., Watts, C., Li, X.-Z., and Zhou, T. (2015). A novel peptide-binding motifs inference approach to understand deoxynivalenol molecular toxicity. Toxins 7, 1989-2005. doi: 10.3390/toxins7061989

Hayat, M. A. (1989). Principles and Techniques of Electron Microscopy: Biological Applications. New York, NY: CRC Press.

He, J., Boland, G., and Zhou, T. (2009). Concurrent selection for microbial suppression of Fusarium graminearum, Fusarium Head Blight and deoxynivalenol in wheat. J. Appl. Microbiol. 106, 1805-1817. doi: 10.1111/j.1365-2672.2009.04147.x

He, Z., Kisla, D., Zhang, L., Yuan, C., Green-Church, K. B., and Yousef, A. E. (2007). Isolation and identification of a Paenibacillus polymyxa strain that coproduces a novel lantibiotic and polymyxin. Appl. Environ. Microbiol. 73, 168-178. doi: 10.1128/AEM.02023-06

Iltis, H. H., and Doebley, J. F. (1980). Taxonomy of Zea (Gramineae). II. Subspecific categories in the Zea mays complex and a generic synopsis. Am. J. Bot. 67, 994-1004. doi: 10.2307/2442442

Janisiewicz, W. J., Jurick, W. M., Vico, I., Peter, K. A., and Buyer, J. S. (2013). Culturable bacteria from plum fruit surfaces and their potential for controlling brown rot after harvest. Postharvest Biol. Technol. 76, 145-151. doi: 10.1016/j.postharvbio.2012.10.004

Jelinek, C. F., Pohland, A., and Wood, G. (1988). Worldwide occurrence of mycotoxins in foods and feeds-an update. J. Assoc. Off. Anal. Chem. 72, 223-230.

Johnston-Monje, D., and Raizada, M. N. (2011). Conservation and diversity of seed associated endophytes in across boundaries of evolution, ethnography and ecology. PLoS ONE 6:e20396. doi: 10.1371/journal.pone.0020396

Johnston-Monje, D., Mousa, W. K., Lazarovits, G., and Raizada, M. N. (2014). Impact of swapping soils on the endophytic bacterial communities of predomesticated, ancient and modern maize. BMC Plant Biol. 14:233. doi: 10.1186/s12870-014-0233-3

Kajimura, Y., and Kaneda, M. (1996). Fusaricidin A, a new depsipeptide antibiotic produced by Bacillus polymyxa kt- 8 taxonomy, fermentation, isolation, structure elucidation and biological activity. J. Antibiot. 49, 129-135. doi: 10.7164/antibiotics.49.129

Kajimura, Y., and Kaneda, M. (1997). Fusaricidins B, C and D, new depsipeptide antibiotics produced by Bacillus polymyxa kt-8: isolation, structure elucidation and biological activity. J. Antibiot. 50, 220-228. doi: 10.7164/antibiotics.50.220

Kebebe, A., Reid, L., Zhu, X., Wu, J., Woldemariam, T., Voloaca, C., et al. (2015). Relationship between kernel drydown rate and resistance to Gibberella Ear Rot in maize. Euphytica 201, 79-88. doi: 10.1007/s10681-014-1185-2

Lange, E. S., Balmer, D., Mauch-Mani, B., and Turlings, T. C. (2014). Insect and pathogen attack and resistance in maize and its wild ancestors, the teosintes. New Phytol. 204, 329-341. doi: 10.1111/nph.13005

Ling, N., Huang, Q., Guo, S., and Shen, Q. (2011). Paenibacillus polymyxa SQR21 systemically affects root exudates of watermelon to decrease the conidial germination of Fusarium oxysporum f. sp. niveum. Plant soil 341, 485-493. doi: $10.1007 /$ s11104-010-0660-3

MacDonald, M. V., and Chapman, R. (1997). The incidence of Fusarium moniliforme on maize from Central America, Africa and Asia during 19921995. Plant Pathol. 46, 112-125. doi: 10.1046/j.1365-3059.1997.d01-200.x

Magnani, G., Cruz, L., Weber, H., Bespalhok, J., Daros, E., Baura, V., et al. (2013). Culture-independent analysis of endophytic bacterial communities associated with Brazilian sugarcane. Genet. Mol. Res. 12, 4549-4558. doi: 10.4238/2013.October.15.3

Matsuoka, Y., Vigouroux, Y., Goodman, M. M., Sanchez, J., Buckler, E., and Doebley, J. (2002). A single domestication for maize shown by multilocus microsatellite genotyping. Proc. Natl. Acad. Sci. U.S.A. 99, 6080-6084. doi: 10.1073/pnas.052125199

Mei, L., Liang, Y., Zhang, L., Wang, Y., and Guo, Y. (2014). Induced systemic resistance and growth promotion in tomato by an indole-3-acetic acidproducing strain of Paenibacillus polymyxa. Ann. Appl. Biol. 165, 270-279. doi: 10.1111/aab.12135

Mousa, W. K., and Raizada, M. N. (2013). The diversity of anti-microbial secondary metabolites produced by fungal endophytes: an interdisciplinary perspective. Front. Microbiol. 4:65. doi: 10.3389/fmicb.2013.00065
Mousa, W. K., and Raizada, M. N. (2015). Biodiversity of genes encoding antimicrobial traits within plant associated microbes. Front. Plant Sci. 6:231. doi: $10.3389 /$ fpls.2015.00231

Moussa, T. A. A., Almaghrabi, O. A., and Abdel-Moneim, T. S. (2013). Biological control of the wheat root rot caused by Fusarium graminearum using some PGPR strains in Saudi Arabia. Ann. Appl. Biol. 163, 72-81. doi: 10.1111/aab.12034

Munkvold, G. P. (2003a). Cultural and genetic approaches to managing mycotoxins in maize. Ann. Rev. Phytopathol. 41, 99-116. doi: 10.1146/annurev.phyto.41.052002.095510

Munkvold, G. P. (2003b). "Epidemiology of Fusarium diseases and their mycotoxins in maize ears," in Epidemiology of Mycotoxin Producing Fungi, eds X. Xu, J. A. Bailey, and B. M. Cooke (Dordrecht: Springer), 705-713.

Naghmouchi, K., Hammami, R., Fliss, I., Teather, R., Baah, J., and Drider, D. (2012). Colistin A and colistin B among inhibitory substances of Paenibacillus polymyxa JB05-01-1. Arch. Microbiol. 194, 363-370. doi: 10.1007/s00203-0110764-z

Paulus, H., and Gray, E. (1964). The biosynthesis of polymyxin B by growing cultures of Bacillus polymyxa. J. Biol. Chem. 239, 865-871.

Piperno, D. R., Ranere, A. J., Holst, I., Iriarte, J., and Dickau, R. (2009). Starch grain and phytolith evidence for early ninth millennium BP maize from the Central Balsas River Valley, Mexico. Proc. Natl. Acad. Sci. U.S.A. 106, 5019-5024. doi: 10.1073/pnas.0812525106

Raza, W., Yang, W., and Shen, Q. (2008). Paenibacillus polymyxa: antibiotics, hydrolytic enzymes and hazard assessment. J. Plant Pathol. 90, 419-430. doi: 10.4454/jpp.v90i3.683

Raza, W., Yang, X., Wu, H., Wang, Y., Xu, Y., and Shen, Q. (2009). Isolation and characterisation of fusaricidin-type compound-producing strain of Paenibacillus polymyxa SQR-21 active against Fusarium oxysporum f. sp. nevium. Eur. J. Plant Pathol. 125, 471-483. doi: 10.1007/s10658-009-9496-1

Raza, W., Yuan, J., Ling, N., Huang, Q., and Shen, Q. (2015). Production of volatile organic compounds by an antagonistic strain Paenibacillus polymyxa WR-2 in the presence of root exudates and organic fertilizer and their antifungal activity against Fusarium oxysporum f. sp. niveum. Biol. Control 80, 89-95. doi: 10.1016/j.biocontrol.2014.09.004

Reid, L., Zhu, X., Parker, A., and Yan, W. (2009). Increased resistance to Ustilago zeae and Fusarium verticilliodes in maize inbred lines bred for Fusarium graminearum resistance. Euphytica 165, 567-578. doi: 10.1007/s10681-0089782-6

Rodrigues, I., and Naehrer, K. (2012). A three-year survey on the worldwide occurrence of mycotoxins in feedstuffs and feed. Toxins 4, 663-675. doi: $10.3390 /$ toxins 4090663

Rosenthal, J. P., and Dirzo, R. (1997). Effects of life history, domestication and agronomic selection on plant defence against insects: evidence from maizes and wild relatives. Evol. Ecol. 11, 337-355. doi: 10.1023/A:1018420504439

Sánchez-Velásquez, L. R., Ezcurra, E., Martínez-Ramos, M., Álvarez-Buylla, E., and Lorente, R. (2002). Population dynamics of Zea diploperennis, an endangered perennial herb: effect of slash and burn practice. J. Ecol. 90, 684-692. doi: 10.1046/j.1365-2745.2002.00702.x

Schaafsma, A. W., Limay-Rios, V., Paul, D. E., and Miller, J. D. (2009). Mycotoxins in fuel ethanol co-products derived from maize: a mass balance for deoxynivalenol. J. Sci. Food Agri. 89, 1574-1580. doi: 10.1002/jsfa.3626

Schmidt, R., Köberl, M., Mostafa, A., Ramadan, E. M., Monschein, M., Jensen, K. B., et al. (2014). Effects of bacterial inoculants on the indigenous microbiome and secondary metabolites of chamomile plants. Front. Microbiol. 5:64. doi: $10.3389 /$ fmicb. 2014.00064

Shi, C., Yan, P., Li, J., Wu, H., Li, Q., and Guan, S. (2014). Biocontrol of Fusarium graminearum growth and deoxynivalenol production in wheat kernels with bacterial antagonists. Int. J. Environ. Res. Public Health 11, 1094-1105. doi: 10.3390/ijerph110101094

Smith, J. S. C., Duvick, D. N., Smith, O. S., Cooper, M., and Feng, L. (2004). Changes in pedigree backgrounds of Pioneer brand maize hybrids widely grown from 1930 to 1999. Crop Sci. 44, 1935-1946. doi: $10.2135 /$ cropsci2004.1935

Sutton, J. (1982). Epidemiology of wheat head blight and maize ear rot caused by Fusarium graminearum. Can. J. Plant Pathol. 4, 195-209. doi: $10.1080 / 07060668209501326$ 
Timmusk, S., Grantcharova, N., and Wagner, E. G. H. (2005). Paenibacillus polymyxa invades plant roots and forms biofilms. Appl. Environ. Microbiol. 71, 7292-7300. doi: 10.1128/AEM.71.11.7292-7300.2005

Timmusk, S., Van West, P., Gow, N., and Paul Huffstutler, R. (2009). Paenibacillus polymyxa antagonizes oomycete plant pathogens Phytophthora palmivora and Pythium aphanidermatum. J. Appl. Microbiol. 106, 1473-1481. doi: 10.1111/j.1365-2672.2009.04123.x

van der Lee, T., Zhang, H., van Diepeningen, A., and Waalwijk, C. (2014). Biogeography of Fusarium graminearum species complex and chemotypes: a review. Food Add. Contam. 32, 53-460. doi: 10.1080/19440049.2014.984244

Voss, K. A. (2010). A new perspective on deoxynivalenol and growth suppression. Toxicol. Sci. 113, 281-283. doi: 10.1093/toxsci/kfp287

Wang, E. T., Tan, Z. Y., Guo, X. W., Rodríguez-Duran, R., Boll, G., and MartínezRomero, E. (2006). Diverse endophytic bacteria isolated from a leguminous tree Conzattia multiflora grown in Mexico. Arch. Microbiol. 186, 251-259. doi: 10.1007/s00203-006-0141-5

Wang, H., Nussbaum-Wagler, T., Li, B., Zhao, Q., Vigouroux, Y., Faller, M., et al. (2005). The origin of the naked grains of maize. Nature 436, 714-719. doi: 10.1038 /nature03863

Wang, K., Kang, L., Anand, A., Lazarovits, G., and Mysore, K. S. (2007). Monitoring in planta bacterial infection at both cellular and whole-plant levels using the green fluorescent protein variant GFPuv. New Phytol. 174, 212-223. doi: 10.1111/j.1469-8137.2007.01999.x
Wegulo, S. N., Bockus, W. W., Nopsa, J. H., De Wolf, E. D., Eskridge, K. M., Peiris, K. H., et al. (2011). Effects of integrating cultivar resistance and fungicide application on Fusarium Head Blight and deoxynivalenol in winter wheat. Plant Dis. 95, 554-560. doi: 10.1094/PDIS-07-10-0495

White, J. F., and Bacon, C. W. (2012). The secret world of endophytes in perspective. Fungal Ecol. 5, 287-288. doi: 10.1016/j.funeco.2012.03.003

Wilson, D. (1995). Endophyte: the evolution of a term, and clarification of its use and definition. Oikos 73, 274-276. doi: 10.2307/3545919

$\mathrm{Xu}$, S. J., and Kim, B. S. (2014). Biocontrol of Fusarium crown and root rot and promotion of growth of tomato by Paenibacillus strains isolated from soil. Mycobiology 42, 158-166. doi: 10.5941/MYCO.2014.42.2.158

Conflict of Interest Statement: The authors declare that the research was conducted in the absence of any commercial or financial relationships that could be construed as a potential conflict of interest.

Copyright (c) 2015 Mousa, Shearer, Limay-Rios, Zhou and Raizada. This is an openaccess article distributed under the terms of the Creative Commons Attribution License (CC BY). The use, distribution or reproduction in other forums is permitted, provided the original author(s) or licensor are credited and that the original publication in this journal is cited, in accordance with accepted academic practice. No use, distribution or reproduction is permitted which does not comply with these terms. 